\title{
S1-Leitlinie: Neurologische Manifestationen bei COVID-19
}

\author{
Leitlinie der Deutschen Gesellschaft für Neurologie
}

\section{Einleitung}

Die Infektion mit dem neuen „severe acute respiratory syndrome coronavirus 2“ (SARS-CoV-2) führt zu einem bisher unbekannten Krankheitsbild, welches als COVID-19 („COrona VIrus Disease 2019“) bezeichnet wird und erstmalig in der Region Hubei in China beschrieben wurde. Die Infektion wurde durch die WHO am 11.03.2020 zur Pandemie erklärt. SARS-

\section{Fachgesellschaft}

Deutsche Gesellschaft für Neurologie in Zusammenarbeit mit der Deutschen Gesellschaft für Neurointensiv- und Notfallmedizin und der Deutschen Gesellschaft für HNO-Heilkunde, Kopf- und Hals-Chirurgie

\section{Federführend}

Prof. Dr. med. Peter Berlit, Generalsekretär, Schriftleiter DGNeurologie, Deutsche Gesellschaft für Neurologie (DGN), Berlin, berlit@dgn.org

\section{Redaktionskomitee} Leitlinienkoordinator

Prof. Dr. med. Peter Berlit, Generalsekretär, Schriftleiter DGNeurologie, Deutsche Gesellschaft für Neurologie (DGN), Berlin Leitliniengruppe

Prof. Dr. med. Julian Bösel, Klinik für Neurologie, Klinikum Kassel, (DGNI)

Prof. Dr. med. Georg Gahn, Neurologische Klinik, Städtisches Klinikum Karlsruhe, (DGNI)

Prof. Dr. med. Stefan Isenmann, Klinik für Neurologie und klinische Neurophysiologie, St. Josef Krankenhaus Moers

Prof. Dr. med. Dr. rer. nat. Dr. h.c. Sven G. Meuth, Klinik für Neurologie mit Institut für Translationale Neurologie, Universitätsklinikum Münster

Prof. Dr. med. Christian Nolte, Klinik für Neurologie mit Experimenteller Neurologie und "Center for Stroke Research" Berlin (CSB) Charité-Universitätsmedizin Berlin, "corporate member of " Freie Universität Berlin, Humboldt-Universität zu Berlin und Berlin „Institute of Health".

Dr. med. Marc Pawlitzki, Klinik für Neurologie mit Institut für Translationale Neurologie, Universitätsklinikum Münster Prof. Dr. med. Felix Rosenow, Epilepsiezentrum Frankfurt Rhein-Main, Zentrum der Neurologie und Neurochirurgie, Universitätsklinikum Frankfurt

Prof. Dr. med. Benedikt Schoser, Friedrich-Baur-Institut an der Neurologischen Klinik, LMU Klinikum München

Prof. Dr. med. Götz Thomalla, Klinik und Poliklinik für Neurologie, Kopf und Neurozentrum, Universitätsklinikum Hamburg-Eppendorf

Prof. Dr. med. Thomas Hummel, Interdisziplinäres Zentrum für Riechen und Schmecken, Universitäts-HNO-Klinik Dresden; Mandatsträger der Deutschen Gesellschaft für HNO-Heilkunde, Kopf- und Hals-Chirurgie e.V.

Die vollständige Leitlinie wurde unter https://dgn.org/leitlinien/ 4101-II-030-144-neurologische-manifestationen-bei-covid-19 am 18.08.2020 publiziert.
CoV-2 gehört $\mathrm{zu}$ den respiratorischen Viren („community acquired respiratory viruses“: CARV), die obere und untere Atemwegsinfektionen auslösen können. Der Erreger zählt zur Gruppe der Coronaviren, die Erkrankungen von einer normalen Erkältung bis zu schweren Krankheitsverläufen verursachen können. Verwandt mit dem SARS-CoV-2-Virus sind die Viren, die das Krankheitsbild des SARS (schweres akutes respiratorisches Syndrom) und des MERS („middle east respiratory syndrome“) verursachen und für die eine Neurotropie nachgewiesen wurde.

Die SARS-CoV-2-Pandemie hat Auswirkungen auf alle Bereiche der Medizin. Sie betrifft direkt und indirekt auch die Versorgung neurologischer Erkrankungen. Es wird diskutiert, dass eine SARS-CoV-2-Infektion mit dem vermehrten Auftreten von neurologischen Manifestationen wie Hirnnervenaffektionen, Enzephalopathien und Enzephalitiden, ischämischen Schlaganfällen und intrazerebralen Blutungen sowie neuromuskulären Erkrankungen assoziiert sein könnte.

Zahlreiche Berichte legen eine Verschlechterung der Versorgung von Patienten mit neurologischen Erkrankungen aufgrund der besonderen Inanspruchnahme der Gesundheitssysteme während der Pandemie dar. Auswirkungen auf die Versorgung sind direkt und indirekt durch Umverteilung von Ressourcen zugunsten von SARS-CoV-2-Patienten und Schutzmaßnahmen für die Patienten und das versorgende Personal erkennbar. Sie betreffen das Handeln der Laien (z. B. Angst vor Ansteckung im Krankenhaus), den Transport ins Krankenhaus und die intrahospitale Notfallversorgung bis hin zur Rehabilitation.

\section{Zielorientierung der Leitlinie}

Diese S1-Leitlinie spricht Handlungsempfehlungen für die Versorgung von Patienten mit SARS-CoV-2-Infektion hinsichtlich neurologischer Manifestationen, von Patienten mit neurologischer Erkrankung mit und ohne SARS-CoV-2-Infektion und für den Schutz des versorgenden Personals aus. Dabei soll diese Leitlinie in der neurologischen Praxis und Klinik einfach anwendbar sein.

\section{Redaktion}

P. Berlit, Berlin

DGNeurologie 2020 · 3 (6): 495-519

https://doi.org/10.1007/s42451-020-00254-x

Online publiziert: 13 . Oktober 2020

(c) DGN 2020 


\section{Versorgungsbereich}

Ambulante und stationäre neurologische Versorgung.

Zwar können Patienten mit neurologischen Symptomen zunächst in ambulanten Arztpraxen oder Notaufnahmen vorstellig werden, von hier aus ist bei Diagnosestellung aber umgehend die Einweisung in eine neurologische Klinik, vorzugsweise mit neurologischer Intensivstation, notwendig. Alle neurologischen Manifestationen erfordern eine rasche stationäre Diagnostik und Therapie als Notfallindikation. Zeitnah sind rehabilitative und sozialmedizinische Maßnahmen $\mathrm{zu}$ initiieren und ambulant fortzusetzen. Ambulante Verlaufskontrollen sind insbesondere zum Ausschluss von Folgeerkrankungen und -schäden erforderlich.

\section{Anwenderzielgruppe/Adressaten}

Die Leitlinie richtet sich an alle an Neurologen, die Patienten mit V.a. oder bestätigter COVID-19-Infektion und neurologischen Symptomen behandeln, und zur Information an alle an der Versorgung dieser Patienten beteiligten Berufsgruppen, zudem an Betroffene und Angehörige. Sie dient zur Information von Leistungserbringern (Krankenkassen, Rentenversicherungsträger).

\section{Schlüsselwörter}

SARS-CoV-2; COVID-19, Anosmie, Hyposmie, Parosmie, Phantosmie, Ageusie, Hypogeusie, Epidemiologie, Enzephalopathie, Zytokinsturm, IL-6; TNF-alpha, Enzephalitis, epileptische Anfälle, Anfallsrezidiv, Arzneimitteinteraktionen, Meningoenzephalitis, Myelitis, Enzephalomyelitis, neuromuskuläre Erkrankungen, Myositis, Myasthenia gravis, GuillainBarré-Syndrom, Miller-Fisher-Syndrom, „critical illness weakness“, „critical illness neuropathy/myopathy“, „intensive care unit acquired weakness", ECMO, Beatmung, Aufwachreaktion, Delir, Status epilepticus, Neuromonitoring, Schlaganfall, intrazerebrale Blutung, intrakranielle Blutung

\section{Kernaussagen}

\section{Enzephalopathie}

- Enzephalopathien kommen bei COVID-19, gerade bei schweren Verläufen, recht häufig vor.

Zustimmung, $90 \%$

- Präsentationen und Verläufe sind höchst heterogen. Starke Zustimmung, $100 \%$

- Für durch SARS-CoV-2 getriggerte Enzephalopathien werden als Pathomechanismen diskutiert: Hypoxie, Sepsis, schwere systemische Inflammation, Nierenversagen und Zytokinsturm.

Starke Zustimmung, $100 \%$

- Biomarker, die in diesem Zusammenhang bei Patienten mit schwerer COVID-19 gefunden wurden, waren IL-2, IL-6, IL-7, GCSF, TNF-alpha1.

Starke Zustimmung, $100 \%$

- Eine belastbare Grundlage für spezifische Therapiemaßnahmen existiert noch nicht.

Zustimmung, $90 \%$

\section{Meningoenzephalitis}

- Bei neu aufgetretenen zentralneurologischen Symptomen, insbesondere bei Bewusstseinsstörungen, akut einsetzenden kognitiven Defiziten sowie bei epileptischen Anfällen, ist eine weiterführende Diagnostik mit zerebraler Bildgebung (MRT), EEG-Untersuchung und Liquordiagnostik notwendig.

Starke Zustimmung, $100 \%$

- Ein negativer MRT- und/oder Liquorbefund schließt die Verdachtsdiagnose nicht aus. Neben der Routineliquor- einschließlich Erregerdiagnostik sollte eine ergänzende Bestimmung von SARS-CoV-2 aus dem Liquor erfolgen.

Zustimmung, $80 \%$

- Kalkuliert sollte bis zum Ausschluss einer Herpesenzephalitis eine Therapie mit einem Antiherpetikum erfolgen. Der Einsatz von Kortikosteroiden in hohen Dosen kann bei anhaltender Persistenz der Symptome versucht werden.

Zustimmung, $90 \%$

\section{Schlaganfall}

- Ischämische Schlaganfälle und seltener auch intrazerebrale Blutungen kommen bei Patienten mit COVID-19-Erkrankung vor und sind mit einem schwereren Verlauf der Erkrankung assoziiert.

Starke Zustimmung, $100 \%$

- Die behandelnden ÄrztInnen von COVID-19-Patienten sollten mögliche zerebrovaskuläre Komplikationen erkennen können und unverzüglich die notwendige Diagnostik veranlassen.

Starke Zustimmung, $100 \%$

- Eine nachgewiesene Infektion mit SARS-CoV-2 oder der Verdacht auf eine solche darf nicht dazu führen, dass Patienten mit akutem Schlaganfall schlechter behandelt werden als andere Schlaganfallpatienten. Unter Einhaltung der entsprechenden Hygienemaßnahmen sollen sie die gleiche Akutdiagnostik und Akutbehandlung erhalten wie alle Schlaganfallpatienten.

Zustimmung, $90 \%$

- Thrombektomien sollten in Intubationsnarkose erfolgen mit videolaryngoskopischer Intubation in Räumlichkeiten mit Absaugung.

Mehrheitliche Zustimmung, $70 \%$

- Weltweit ist die Anzahl der Patienten, die wegen eines Schlaganfalls im Krankenhaus behandelt werden, unter der COVID19-Pandemie zurückgegangen. Es ist in der Pandemie eine wichtige Aufgabe für alle in der Schlaganfallversorgung tätigen ÄrztInnen, die hohe Qualität der Versorgung zerebrovaskulärer Erkrankungen in Deutschland auch unter erschwerten Bedingungen bestmöglich aufrechtzuerhalten.

Starke Zustimmung, $100 \%$

\section{Akute disseminierte Enzephalomyelitis}

- Neu aufgetretene multifokale neurologische Symptome lassen an eine akute disseminierte Enzephalomyelitis (ADEM) denken, sodass eine rasche Diagnostik inklusive MRT und Liquoranalyse eingeleitet werden sollte.

Starke Zustimmung, $100 \%$

- Die MRT-Bildgebung mit Kontrastmittelgabe ist zur Detektion entzündlicher Läsionen essenziell. Eine ergänzende blu- 
tungssensitive Sequenz hilft zum Nachweis einer hämorrhagischen Komponente.

Starke Zustimmung, $100 \%$

- Ein unauffälliger Liquorbefund spricht nicht gegen die Diagnose einer ADEM.

Zustimmung $90 \%$

- Therapeutisch sollte initial ein 3- bis 5-tägiger Zyklus mit Methylprednisolon (1g/Tag) i.v. erfolgen. Bei persistierenden Symptomen gibt es Hinweise für ein Ansprechen auf i.v. Immunglobuline.

Zustimmung, $80 \%$

\section{Epilepsie}

- Bei Auftreten epileptischer Anfälle oder eines Status epilepticus während einer COVID-19-Erkrankung soll geklärt werden, ob es sich um einen akut symptomatischen (erstmaligen) Anfall handelt oder um ein Rezidiv bei vorbekannter Epilepsie.

Starke Zustimmung, $100 \%$

- Neben Anamnese und ggf. Fremdanamnese und klinischer Untersuchung soll eine akute zerebrale Bildgebung (möglichst MRT) erfolgen.

Starke Zustimmung, $100 \%$

- Bei unklarer Bewusstseinsstörung soll ein EEG durchgeführt werden, um epilepsietypische Aktivität nachzuweisen und zu lokalisieren und um einen nichtkonvulsiven Status epilepticus nachzuweisen bzw. auszuschließen.

Starke Zustimmung, $100 \%$

- Bei der Ableitung von EEG sollte auf Hyperventilation möglichst verzichtet werden.

Zustimmung, $80 \%$

- Die Behandlung von akut symptomatischen Anfällen oder eines Status epilepticus soll entsprechend der jeweiligen Leitlinie erfolgen.

Starke Zustimmung, $100 \%$

- Kontraindikationen und Wechselwirkungen von zur COVID19-Erkrankung eingesetzten Substanzen mit Antikonvulsiva sollen bei der Therapie berücksichtigt werden.

Starke Zustimmung, $100 \%$

- Da Infektionen Anfälle triggern können, sollte bei Patienten mit vorbekannter Epilepsie besprochen werden, was bei einer SARS-CoV-2-Infektion ggf. unternommen werden sollte. Bei Patienten mit bekannten fieberassoziierten Anfällen sollte ein NSAID (bspw. Paracetamol) gegeben werden.

Zustimmung, $90 \%$

\section{Störungen der Chemosensorik}

- Eine Infektion mit SARS-CoV-2 kann zu Störungen der Chemosensorik führen, mit Hyp- und häufig Anosmie.

Starke Zustimmung, $100 \%$

- Während der Pandemie ist eine plötzlich neu aufgetretene Riechstörung (Anosmie) bei freier Nasenatmung sehr wahrscheinlich Ausdruck einer Infektion mit SARS-CoV-2.

Zustimmung, $82 \%$

- Eine während der Pandemie neu auftretende Riechstörung/ Anosmie sollte daher Anlass geben zu (Zustimmung, $82 \%$ ):

- Selbstisolation/Quarantäne

- Testung auf SARS-CoV-2 (über telefonische Kontaktaufnahme mit Hausarzt/Gesundheitsamt)
Hier steht eine Anzeige.

Springer 
- Verwendung persönlicher Schutzausrüstung bei professionellem Kontakt mit Betroffenen.

- Riechstörungen können anderen Erkrankungssymptomen vorangehen und sind daher epidemiologisch relevant (Frühidentifikation neuer Hotspots)

Zustimmung, $91 \%$

- Die Riechstörung bei COVID-19 scheint meist vorübergehend zu sein. Ob es regelhaft zu einer vollständigen Restitution kommt, kann noch nicht abschließend beurteilt werden. Starke Zustimmung, $100 \%$

- Sollte sich die Riechfunktion nicht binnen 3-4 Wochen wieder normalisieren, wird eine neurologische und HNO-ärztliche Vorstellung mit weiterer Diagnostik empfohlen.

Starke Zustimmung, $100 \%$

\section{Nerven- und Muskelaffektionen}

- Myalgien, Fatigue und HyperCKämie stellen als Trias die häufigste Form (40-70\%) einer Skelettmuskelaffektion in COVID-19-Kohorten dar.

Starke Zustimmung, $100 \%$

- Eine intensivmedizinpflichtige COVID-19-Erkrankung mit invasiver Beatmung kann zur ICUAW („ICU-acquired weakness" [ICU: Intensivstation]), einem Krankheitsbild, bei dem die CIP („critical illness polyneuropathy“) und die CIM („critical illness myopathy“) ineinandergreifen, führen.

Starke Zustimmung, $100 \%$

- Es scheint kein massiv erhöhtes Risiko für neuromuskuläre Patienten unter einer SARS-CoV-2-Infektion zu bestehen.

Zustimmung, $90 \%$

\section{Guillain-Barré-Syndrom (akute inflammatorische demyelinisierende Polyneuritis - AIDP)}

- Ein Guillain-Barré-Syndrom (GBS) stellt eine ernste Komplikation der COVID-19-Erkrankung dar und kann bereits wenige Tage nach den ersten respiratorischen Symptomen auftreten.

Starke Zustimmung, $100 \%$

- Bei Erstdiagnose eines GBS während der Pandemie sollte eine SARS-CoV-2-Testung erfolgen.

Mehrheitliche Zustimmung, 70\%

- Klinisch sind milde Verläufe bis hin zu schweren Hirnnervenbeteiligungen möglich.

Zustimmung, $90 \%$

- Elektroneurographisch dominiert meist ein demyelinisierendes Schädigungsmuster, wobei auch axonale Verläufe berichtet werden.

Starke Zustimmung, $100 \%$

- Eine Liquordiagnostik zum Ausschluss einer infektiösen Genese ist notwendig. Meist zeigt sich eine zytoalbuminäre Dissoziation.

Starke Zustimmung, $100 \%$

- Es empfiehlt sich eine serologische Testung von Gangliosidantikörpern.

Starke Zustimmung, $100 \%$

- Therapeutisch sind i.v. Immunglobuline sowie Plasmaaustauschverfahren als gleichwertig anzusehen und zeitnah $\mathrm{zu}$ initiieren.

Zustimmung, $90 \%$
- Ein engmaschiges Monitoring und die Verfügbarkeit von intensivmedizinischen Maßnahmen sind essenziell.

Starke Zustimmung, $100 \%$

\section{Neurologische Intensivmedizin}

- Neurologische Manifestationen von COVID-19 können leicht in der schwerwiegenden, pulmonal dominierten Intensivsituation maskiert bleiben. Deshalb muss aktiv nach einer Mitbeteiligung des zentralen oder peripheren Nervensystems gesucht werden.

Starke Zustimmung, $100 \%$

- Eine invasive Beatmung mit PEEP („positive end-expiratory pressure"), einer permissiven Hyperkapnie oder in Bauchlagerung können zu einer Erhöhung des intrakraniellen Drucks führen, aber dennoch notwendig sein.

Starke Zustimmung, $100 \%$

- Ein multimodales Neuromonitoring (z. B. ICP-, CPP-Messung, NIRS, transkranieller Doppler/Duplex, sonographische Messung des Sehnervenscheidendurchmessers) ermöglicht das differenzierte therapeutische Vorgehen bei Patienten mit erhöhtem intrakraniellem Druck.

Zustimmung, $80 \%$

- Bei Verdacht auf eine zerebrale oder auch spinale Beteiligung durch COVID-19 sollten ein CT oder ein MRT durchgeführt werden. Bei manchen Patienten, die aufgrund schweren intensivmedizinischen Verlaufs und/oder Analgosedierung nicht zuverlässig klinisch untersuchbar sind, kann dies auch prophylaktisch angezeigt sein (z. B. zerebrales CT vor ECMO). Starke Zustimmung, $100 \%$

\section{Risiko und Verlauf von COVID-19 unter einer Immuntherapie}

- Aus den bisherigen Berichten kann kein erhöhtes Risiko für eine COVID-19-Erkrankung unter einer Immuntherapie abgeleitet werden.

Starke Zustimmung, $100 \%$

- Es empfiehlt sich daher, Immuntherapien fortzusetzen. Individuelle Risikofaktoren wie Patientenalter, Morbidität und regionale Prävalenzen von COVID-19 sollten jedoch zur Einschätzung des individuellen Patientenrisikos miteinbezogen und im Einzelfall Deeskalationsstrategien wie eine Therapieumstellung oder eine Intervallverlängerung evaluiert werden.

Starke Zustimmung, $100 \%$

- Im Fall einer COVID-19-Erkrankung sollten insbesondere Aspekte wie Krankheitsaktivität der zugrunde liegenden neurologischen Erkrankung sowie der bisherige Therapieverlauf berücksichtigt und die Immuntherapie ggf. pausiert werden. Starke Zustimmung, $100 \%$

\section{Neuroimmunologische Manifestationen}

Bearbeitet von M. Pawlitzki und Sven G. Meuth, Münster

\section{1 (Infektiös-)entzündliche Komplikationen}

\section{a) (Meningo-)Enzephalitis}

Bisher existieren nur wenige Fallberichte über das Auftreten einer (Meningo-)Enzephalitis im Rahmen von COVID-19 [1-5]. Ungeklärt ist weiterhin, ob es sich dabei um eine direkte SARS- 
CoV-2-Infektion des ZNS oder um ein autoimmunes, postinfektiöses Geschehen handelt. Unter Berücksichtigung der bisherigen Erfahrungen mit SARS-CoV-1 ist eine zerebrale Infektion zwar möglich, aber eher selten [6]. Das meist subakute Auftreten von neurologischen Symptomen wenige Tage nach den oft milden respiratorischen Symptomen spricht zwar für ein direkt infektiöses Geschehen. Andererseits wurden auch nach überstandenen pulmonalen SARS-CoV-2-Infektionen Enzephalitiden berichtet.

Diagnostik. (Sub-)akut auftretende schwere kognitive Defizite sowie Bewusstseinseintrübungen stehen meist im Vordergrund. Doch auch (nicht-)konvulsive Anfälle oder gar ein akinetischer Mutismus können das Erstsymptom darstellen. Ein verzögertes Weaning oder ein anhaltendes Delir nach Extubation sollten differenzialdiagnostisch auch an eine neurologische Mitbeteiligung denken lassen. Da die Symptome jedoch teils auch wenige Tage nach einer bestätigten, bis dahin milde verlaufenen COVID-19-Erkrankung auftreten können, sollte bei erstdiagnostizierter Enzephalitis auch an eine entsprechende SARS-CoV-2Infektion gedacht werden.

Es gibt bisher keine spezifischen MRT-Befunde. Es sind kortikale Hyperdensitäten mit partieller Kontrastmittelaufnahme wie auch flächige bilaterale Marklagerhyperintensitäten zu finden, wobei unauffällige Befunde häufig sind.

Elektroenzephalographisch werden generalisierte Veränderungen im Sinne einer Enzephalopathie beschrieben, aber auch fokale Herdbefunde bis hin $\mathrm{zu}$ epilepsietypischen Potenzialen können auftreten. Der Liquorzellbefund reicht von einem normwertigen Zellbefund bis hin zu einer lymphozytären Pleozytose von teils $>100$ Zellen/ $\mu$ l. Eine Blut-Liquor-SchrankenStörung kann ebenfalls vorliegen. Der direkte Erregernachweis mittels PCR gelingt in den wenigsten Fällen. Grundsätzlich sollte immer eine Standarderregerdiagnostik, insbesondere auf Herpesviren, erfolgen. Darüber hinaus ist eine Autoantikörperdiagnostik aus Serum und Liquor zum Ausschluss einer Autoimmunenzephalitis sinnvoll.

Therapie. Die bisherigen Therapieschemata sind nicht einheitlich. Bei Verdacht auf eine Enzephalitis durch Viren der Herpesgruppe sollte ohne zeitlichen Verzug ein Antiherpetikum (in der Regel Aciclovir) i.v. verabreicht werden. Ist auch eine bakterielle Genese differenzialdiagnostisch nicht sicher auszuschließen, sollten zunächst zusätzlich Antibiotika (z. B. Zephalosporine der Gruppe 3 plus Ampicillin) verabreicht werden. Bei negativer Erregerdiagnostik und Beschwerdepersistenz kann eine Hochdosistherapie mit Methylprednisolon ( $1 \mathrm{~g} / \mathrm{Tag}$ ) über 3-5 Tage versucht werden. Es liegen auch Fallberichte für den anschließenden Einsatz von Plasmaaustauschverfahren vor, wobei in den entsprechenden Fällen zumindest liquordiagnostisch kein (infektiös-)entzündliches Muster zu erkennen war.

\section{2 (Autoimmun-)entzündliche Erkrankungen}

\section{a) Guillain-Barré-Syndrom (akute inflammatorische demyelinisierende Polyneuritis - AIDP)}

Es gibt zunehmende Berichte über das Auftreten eines GuillainBarré-Syndroms (GBS) im Rahmen einer COVID-19-Erkrankung [2, 7-20]. Wie im Rahmen von anderen Viruserkrankun- gen ist von einer postinfektiösen Genese auszugehen, wobei die Latenz zwischen Erstmanifestation von COVID-19 und dem Auftreten eines GBS sehr kurz zu sein scheint.

Diagnostik. Die neurologischen Symptome treten meist in einer Zeitspanne von ca. 5-10 Tagen nach einer COVID-19Diagnose auf, wobei sich auch Wochen nach durchgemachter Infektion ein GBS entwickeln kann. Aufgrund der Gefahr von kardiovaskulären Komplikationen, insbesondere einer respiratorischen Insuffizienz und von kardialen Arrhythmien, sollte eine rasche Diagnostik eingeleitet werden, um zeitnah die Akuttherapie und ggf. eine intensivmedizinische Betreuung zu initiieren.

Das klinische Bild reicht von milden sensiblen Defiziten in Form von distal symmetrisch aufsteigenden Par- und Hypästhesien bis hin $\mathrm{zu}$ schweren Tetraparesen. Auch eine primäre Hirnnervenbeteiligung in Form von bilateralen Fazialisparesen, Augenmuskelparesen oder einem Miller Fisher-Syndrom wurden berichtet. Nicht selten führt der rasch progrediente Verlauf $\mathrm{zu}$ einer respiratorischen Insuffizienz und sogar zum Versterben der Patienten. Bei bereits intensivmedizinisch betreuten Patienten sollte insbesondere beim Auftreten von o.g. Symptomen im Verlauf, speziell bei respiratorischer Verschlechterung, an ein postinfektiöses GBS gedacht werden.

Bisher lässt sich kein Zusammenhang zwischen der Schwere der COVID-19-Erkrankung und dem Auftreten bzw. dem Verlauf eines GBS abzeichnen. Teilweise wurde erst retrospektiv die Diagnose einer (durchgemachten) COVID-19-Erkrankung gestellt. Daher ist bei jeder neuen GBS-Diagnose auch eine entsprechende SARS-CoV-2-Testung zu empfehlen.

Elektroneurographisch zeigt sich meist das typische Muster einer symmetrischen, demyelinisierenden sensomotorischen Polyneuropathie. Auch axonale Schädigungsmuster können bei schweren Verläufen im Vordergrund stehen. Elektromyographische Untersuchungen sind hierbei im Verlauf hinsichtlich der Prognose empfehlenswert.

Eine „zytoalbuminäre Dissoziation“ mit Gesamtproteinerhöhung und normaler bis allenfalls leicht erhöhter Zellzahl $(0-10$ Zellen/ $\mu \mathrm{l})$ ist meist im Liquor nachweisbar. Eine intrathekale Immunglobulinsynthese und isolierte oligoklonale Banden im Liquor sind untypisch. Ergänzend sollte serologisch eine Bestimmung von Gangliosidantikörpern erfolgen, insbesondere bei einer Hirnnervenbeteiligung. In einer spinalen MRTBildgebung kann teils die Kontrastaufnahme der lumbosakralen Nervenwurzeln dokumentiert werden.

Therapie. Das Therapiemanagement unterscheidet sich nicht von dem bisherigen Vorgehen beim GBS. Bisher erfolgte meist der primäre Einsatz von i.v. Immunglobulinen $(0,4 \mathrm{~g} / \mathrm{kgKG})$ aufgrund des vermuteten Erhalts der Immunkompetenz bei COVID-19. Plasmaaustauschverfahren und Immunglobuline sind jedoch weiterhin als gleichwertig anzusehen. Auf Kortikosteroide sollte verzichtet werden. Hinsichtlich des Monitorings und der symptomatischen Therapie sei auf die entsprechende Leitlinie Therapie akuter und chronischer immunvermittelter Neuropathien und Neuritiden verwiesen. 


\section{b) Akute disseminierte Enzephalomyelitis (ADEM)}

Die ADEM tritt als seltene Komplikation nach einem erlittenen Infekt oder einer Impfung auf und ist in der Regel durch einen monophasischen Verlauf gekennzeichnet. Bisher existieren wenige Fallberichte über ADEM-ähnliche Verläufe im zeitlichen Zusammenhang mit einer COVID-19-Erkrankung [12, 21-23]. Auffallend ist, dass sich die bisher Betroffenen im mittleren bis höheren Erwachsenenalter befanden.

Diagnostik. Die klinische Symptomatik variiert bei einer ADEM deutlich, umfasst jedoch teils schwere fokalneurologische Defizite (Optikusneuritiden, schwere Paresen) sowie ein subakutes enzephalopathisches Syndrom.

Entsprechend zügig sollte eine kranielle MRT mit Kontrastmittelgabe erfolgen. Charakteristisch sind dabei große, teils Kontrastmittel aufnehmende Läsionen im Marklager sowie in den Basalganglien, wobei auch Entmarkungen im Hirnstamm auftreten können. Ergänzend sollte eine blutungssensitive MRT-Sequenz (T2* oder SWI) gefahren werden, um schwere hämorrhagische Verläufe im Sinne einer akuten hämorrhagischen Leukenzephalitis zu identifizieren $[22,23]$.

In der Liquordiagnostik zeigen sich meist eine Pleozytose von $<100$ Zellen/ $\mu$ l und teilweise eine leichte Blut-LiquorSchranken-Störung. Das Fehlen von isolierten oligoklonalen Banden im Liquor ist häufig. Differenzialdiagnostisch sollte eine Testung von Aquaporin-4- oder Myelinoligodendrozytenglykoprotein(MOG)-Antikörpern erfolgen, um nicht die Erstmanifestation einer meist relapsierenden Neuromyelitis-opticaSpektrum-Erkrankung (NMOSD) oder einer MOG-Enzephalomyelitis zu übersehen.

Therapie. Therapeutisch ist initial eine Gabe von hochdosierten Kortikosteroiden (1-2g/Tag) i.v. über 3-5 Tage mit oder ohne orales Ausschleichen zu empfehlen. Bei unzureichendem Ansprechen erwies sich die Gabe von Immunglobulinen (0,4 g/ kgKG i.v.) als Erfolg versprechend.

Implikationen für die Anwendung von Immuntherapien in Zeiten von COVID-19. Immuntherapien stellen die therapeutische Grundlage bei einer Vielzahl neurologischer Erkrankungen dar, mit kontinuierlicher Zunahme zugelassener Indikationen. Neben den klassischen immunsuppressiven Therapien steigt die Zahl selektiver Behandlungsstrategien, die jedoch teils ebenso einen anhaltenden Einfluss auf die Immunkompetenz haben. Aktuell lässt sich auf Grundlage der wenigen Fallberichte einer COVID-19-Erkrankung unter einer Immuntherapie nicht schlussfolgern, ob diese mit einem erhöhten Risiko für COVID-19 oder mit einer schlechteren Prognose einhergeht [24-29]. Für die multiple Sklerose (MS) existieren jedoch epidemiologische Daten von regionalen Schwerpunktzentren aus Italien und Chile, aus denen eine geringe Inzidenz von COVID19-Fällen hervorgeht [30, 31]. Eine Abfrage von 10 MS-Zentren in China bezog darüber hinaus mehr als 2000 Patienten mit einer NMOSD unter entsprechender Immuntherapie mit ein, von denen nur 2 Patienten eine COVID-19-Erkrankung erlitten [32]. Aufgrund der geringen Evidenz können jedoch nur potenzielle Risiken anhand der unterschiedlichen Wirkmechanismen und bisherigen Erfahrungen mit anderen Infektionserkrankungen abgeleitet werden [33].
Tab. 1 enthält eine Übersicht über die aktuell angewandten Immuntherapien bei neurologischen Krankheitsbildern und Empfehlungen in Zeiten der COVID-19-Pandemie und im Fall einer akuten COVID-19-Erkrankung.

\section{Akute Enzephalopathie und akute Enzephalitis \\ Bearbeitet von Julian Bösel, Kassel}

\subsection{Enzephalopathie}

\section{Definition und Klassifikation}

Die Enzephalopathie ist recht umfassend und auch etwas unscharf definiert als meist reversible diffuse Hirnfunktionsstörung ohne strukturelle oder direkt (!) infektiöse Ursache. Man unterscheidet die folgenden Enzephalopathien, die Zusatzangaben in Klammern sind nur eine Auswahl möglicher Ursachen: - metabolische Enzephalopathie (bei Hormon- oder Stoffwechselentgleisungen)

- toxische Enzephalopathie (bei Drogen- oder Medikamentenintoxikationen)

- Wernicke-Enzephalopathie (bei Thiaminmangel)

- hepatische Enzephalopathie (bei Leberversagen)

- urämische Enzephalopathie (bei Nierenversagen)

- septische Enzephalopathie (bei Sepsis)

- hypoxische Enzephalopathie (bei Hypoxie, z. B. nach Herz-/ Lungenversagen)

Die Pathomechanismen sind dabei großteils nur lückenhaft verstanden. Systemische Infektionen können eine septische oder über Multiorganversagen auch andersartige Enzephalopathie triggern.

Für durch SARS-CoV-2 getriggerte Enzephalopathien werden als Pathomechanismen diskutiert: Sepsis, schwere systemische Inflammation, Nierenversagen und Zytokinsturm. Biomarker, die in diesem Zusammenhang bei Patienten mit schwerer COVID-19 gefunden wurden, waren u. a. IL-2, IL-6, IL-7, GCSF, TNF-alpha [34].

\section{Diagnostik}

Die Symptome einer Enzephalopathie können sehr unterschiedlich sein. Häufig sind darunter:

- neuropsychologische Auffälligkeiten (z.B. Wesensänderung, Fehlverhalten)

- Agitation und Delir

- extrapyramidal-motorische Bewegungsstörungen, Koordinationsstörungen

- qualitative und quantitative Bewusstseinsstörungen

- epileptische Anfälle

- fokalneurologische Defizite

Bei Verdacht auf eine Enzephalopathie ist die folgende Zusatzdiagnostik indiziert:

- Labordiagnostik (inkl. Elektrolyte, Nieren- und Leberwerte, BB, CRP, CK, NSE)

- erweiterte Labordiagnostik (z.B. auf Hormone, Antikörper, Zytokine)

- CT oder besser MRT (mit Frage nach strukturellen Läsionen und Hirnödem)

- Lumbalpunktion und Liquoranalyse (zum Ausschluss Meningoenzephalitis) 
Tab. 1 Übersicht der am häufigsten angewandten Immuntherapien bei neurologischen Erkrankungen und entsprechende Empfehlungen hinsichtlich deren Anwendung in Zeiten von COVID-19

\begin{tabular}{|c|c|c|c|}
\hline Substanzen & Indikationen & $\begin{array}{l}\text { Therapiestrategien in Zeiten von } \\
\text { COVID-19 }\end{array}$ & $\begin{array}{l}\text { Therapiestrategien im Fall einer } \\
\text { COVID-19-Infektion }\end{array}$ \\
\hline \multicolumn{4}{|c|}{ Interferenz mit der DNA-Synthese } \\
\hline Azathioprin & $\begin{array}{l}\text { MG, NMOSD, PACNS, IIM, AIE, sekundäre } \\
\text { ZNS-Vaskulitiden/Kollagenosen, Neurosar- } \\
\text { koidose }\end{array}$ & Fortsetzung & Pausieren \\
\hline Methotrexat & $\begin{array}{l}\text { MG, NMOSD, PACNS, IIM, AIE, sekundäre } \\
\text { ZNS-Vaskulitiden/Kollagenosen, Neurosar- } \\
\text { koidose }\end{array}$ & Fortsetzung & Pausieren \\
\hline Cyclophosphamid & $\begin{array}{l}\text { PACNS, AIE, sekundäre ZNS-Vaskulitiden/ } \\
\text { Kollagenosen }\end{array}$ & $\begin{array}{l}\text { Fortsetzung; bei langjährigem stabilem } \\
\text { Krankheitsverlauf Deeskalationstherapien }\end{array}$ & Pausieren \\
\hline Mitoxantron & SPMS & $\begin{array}{l}\text { Therapiealternativen; bei langjährigem } \\
\text { stabilem Krankheitsverlauf Dosisreduktion } \\
\text { oder Absetzen }\end{array}$ & Pausieren \\
\hline Teriflunomid & RRMS & Fortsetzung & $\begin{array}{l}\text { Fortsetzung; bei ausgeprägter Lym- } \\
\text { phopenie pausieren }\end{array}$ \\
\hline $\begin{array}{l}\text { Mykophenol- } \\
\text { atmofetil }\end{array}$ & $\begin{array}{l}\text { MG, NMOSD, PACNS, IIM, sekundäre } \\
\text { ZNS-Vaskulitiden/Kollagenosen, Neuro- } \\
\text { sarkoidose }\end{array}$ & Fortsetzung & $\begin{array}{l}\text { Fortsetzung; bei ausgeprägter Lym- } \\
\text { phopenie pausieren }\end{array}$ \\
\hline Cladribin & RRMS & Zyklus bei Krankheitsstabilität verzögern & Pausieren; Therapiealternativen \\
\hline \multicolumn{4}{|c|}{ Immunzelldepletion durch Pulstherapien } \\
\hline Rituximab & $\begin{array}{l}\text { MG, NMOSD, PACNS, IIM, AIE, sekundäre } \\
\text { ZNS-Vaskulitiden/Kollagenosen, CIDP }\end{array}$ & $\begin{array}{l}\text { Zyklus bei Krankheitsstabilität verzögern; } \\
\text { CD19-B-Zell-Monitoring }\end{array}$ & Pausieren; Therapiealternativen \\
\hline Ocrelizumab & RRMS, PPMS & $\begin{array}{l}\text { Zyklus bei Krankheitsstabilität ver- } \\
\text { zögern, insbesondere bei PPMS } \\
\text { CD19-B-Zell-Monitoring }\end{array}$ & Pausieren; Therapiealternativen \\
\hline Inebilizumab & NMOSD & $\begin{array}{l}\text { Zyklus bei Krankheitsstabilität verzögern; } \\
\text { CD19-B-Zell-Monitoring }\end{array}$ & Pausieren; Therapiealternativen \\
\hline Alemtuzumab & RRMS & $\begin{array}{l}\text { Zyklus bei Krankheitsstabilität verzögern; } \\
\text { Therapiealternativen }\end{array}$ & Pausieren; Therapiealternativen \\
\hline \multicolumn{4}{|c|}{ Sequestrierung von Leukozyten in der Peripherie } \\
\hline $\begin{array}{l}\text { Fingolimod/ } \\
\text { Ozanimod }\end{array}$ & RRMS & Fortsetzung & $\begin{array}{l}\text { Fortsetzung, ggf. Pausieren für weni- } \\
\text { ge Wochen }\end{array}$ \\
\hline Siponimod & SPMS & Fortsetzung & $\begin{array}{l}\text { Fortsetzung, Pausieren jedoch ver- } \\
\text { tretbar }\end{array}$ \\
\hline Natalizumab & RRMS & Fortsetzung, ggf. Zyklusverlängerung & $\begin{array}{l}\text { Fortsetzung, ggf. Zyklusverlänge- } \\
\text { rung }\end{array}$ \\
\hline \multicolumn{4}{|c|}{ Pleiotrope Immunmodulation } \\
\hline Glatirameracetat & RRMS & Fortsetzung & Fortsetzung \\
\hline Dimethylfumarat & RRMS & $\begin{array}{l}\text { Fortsetzung; Pausieren bei ausgeprägter } \\
\text { Lymphopenie }\end{array}$ & $\begin{array}{l}\text { Fortsetzung; Pausieren bei ausge- } \\
\text { prägter Lymphopenie }\end{array}$ \\
\hline \multicolumn{4}{|c|}{ Zytokine als Immuntherapie } \\
\hline IFN- $\beta$ & RRMS, SPMS & Fortsetzung & Fortsetzung \\
\hline $\begin{array}{l}\text { Tocilizumab/ } \\
\text { Satralizumab }\end{array}$ & NMOSD & Fortsetzung & Fortsetzung \\
\hline \multicolumn{4}{|c|}{ Komplementinhibition } \\
\hline Eculizumab & MG, NMOSD & Fortsetzung & Fortsetzung \\
\hline \multicolumn{4}{|c|}{ Blockade intrazellulärer Signalwege } \\
\hline Ciclosporin A & MG, IIM & Fortsetzung & Fortsetzung, ggf. Dosisreduktion \\
\hline \multicolumn{4}{|l|}{ Akuttherapien } \\
\hline GKS-Pulstherapie & $\begin{array}{l}\text { MS, MG, NMOSD, PACNS, IIM, AIE, sekun- } \\
\text { däre ZNS-Vaskulitiden/Kollagenosen, } \\
\text { Neurosarkoidose }\end{array}$ & Nur bei akuter Krankheitsaktivität & Pausieren, Dosisreduktion \\
\hline $\begin{array}{l}\text { GKS-Dauertherapie/ } \\
\text { Tapering }\end{array}$ & $\begin{array}{l}\text { NMOSD, MG, PACNS, IIM, CIDP, sekundäre } \\
\text { ZNS-Vaskulitiden/Kollagenosen, Neurosar- } \\
\text { koidose }\end{array}$ & $\begin{array}{l}\text { Bei Krankheitsstabilität Dosisreduktion } \\
\text { erwägen }\end{array}$ & $\begin{array}{l}\text { Bei Krankheitsstabilität Dosisredukti- } \\
\text { on erwägen }\end{array}$ \\
\hline
\end{tabular}


Tab. 1 (Fortsetzung)

\begin{tabular}{l|l|l|l} 
Substanzen & Indikationen & $\begin{array}{l}\text { Therapiestrategien in Zeiten von } \\
\text { COVID-19 }\end{array}$ & $\begin{array}{l}\text { Therapiestrategien im Fall einer } \\
\text { COVID-19-Infektion }\end{array}$ \\
\hline IVIG & MG, IIM, CIDP, GBS & Fortsetzung, ggf. Zyklusverlängerung & $\begin{array}{l}\text { Fortsetzung, ggf. Zyklusverlänge- } \\
\text { rung }\end{array}$ \\
$\begin{array}{l}\text { Plasmapherese/ } \\
\text { Immunadsorption }\end{array}$ & MS, MG, NMOSD, AIE, IIM, GBS & Fortsetzung & $\begin{array}{l}\text { Fortsetzung bei entsprechender } \\
\text { Indikation }\end{array}$ \\
\hline
\end{tabular}

AIE Autoimmunenzephalitis, GBS Guillain-Barré-Syndrom, GKS Glukokortikosteroide, CIDP chronische inflammatorische demyelinisierende Polyneuropathie, IFN- $\beta$ Betainterferon, IIM idiopathisch inflammatorische Myopathie, IVIG intravenöse Immunglobuline, MG Myasthenia gravis, MS multiple Sklerose, NMOSD Neuromyelitis-optica-Spektrum-Erkrankung, PACNS primäre Angiitis des zentralen Nervensystems, PPMS primär chronisch progrediente multiple Sklerose, RRMS schubförmig remittierende multiple Sklerose, SPMS sekundär chronisch progrediente multiple Sklerose

- EEG (zum Monitoring der diffusen Hirnfunktionsstörung, Klären von - auch subklinischen - epileptischen Anfällen oder Status epilepticus)

- ggf. Ganzkörper-CT (zur Suche nach Organstörung, Infektfoci oder Tumoren)

- SSEP (zusätzlich bei hypoxischer E. zur Prognoseabschätzung)

Die Labordiagnostik ist nicht selten der entscheidende Schlüssel zu Diagnose und Differenzierung der Enzephalopathie, die Liquordiagnostik dient eher dem Ausschluss der direkten Hirninfektion oder dem Nachweis von Destruktionsmarkern nach Hypoxie. Das EEG ist sehr oft pathologisch, wobei die Veränderungen von unspezifischen Allgemeinveränderungen über triphasische Wellen (besonders bei hepatischen oder urämischen Enzephalopathien) bis zu eindeutigen Anfalls- oder Statusmustern führen können. CT und MRT können normal sein, lokales Hirnödem und/oder (multi-)fokale Kontrastmittelaufnahme zeigen oder auch hämorrhagisch-nekrotische Veränderungen bieten. Bei der hypoxischen Enzephalopathie zeigen sich eine Entdifferenzierung der Mark-Rinden-Grenze kortikal und im Bereich der Basalganglien, mitunter auch ein generalisiertes Hirnödem.

Häufigere Differenzialdiagnosen zur Enzephalopathie sind Enzephalitis, Hirnvenen- und Sinusthrombose, Hirntumoren oder -metastasen sowie Psychosen oder Delir.

\section{Therapie}

Die Therapie der Enzephalopathie richtet sich nach der Ursache und besteht z. B. bei der septischen E. in der Sepsistherapie, bei der metabolischen E. im Ausgleich von Glukose-/Elektrolyt-/ Flüssigkeitshaushalt, bei der toxischen E. im Ausschalten der Noxe. Eine kausale Therapie bei hypoxischer E. ist nicht bekannt, eine 24-stündige Hypothermie kann versucht werden.

Die symptomatische Therapie besteht ganz besonders aus der Kontrolle der allgemeinen Homöostase (Elektrolyte, Flüssigkeit, Temperatur), der neuroleptischen oder antidepressiven Therapie von psychotischen Krankheitsanteilen, und der antikonvulsiven Therapie epileptischer Anfälle. Bei schweren Verläufen ist eine supportive Intensivtherapie angebracht inklusive ggf. Intubation und Beatmung, Thromboseprophylaxe, Neuromonitoring, ggf. eskalierende Therapie von Hirnödem, erhöhtem intrakraniellem Druck und Status epilepticus.

Bei der SARS-CoV-2-getriggerten Enzephalopathie wäre die systemische Therapie der Viruserkrankung entscheidend, die noch zu etablieren ist. Bei Vermutung autoimmuner Krankheitsanteile könnten kombinierend Immuntherapien wie hoch- dosierte Kortikosteroide, z. B. Dexamethason, und Plasmapherese angewandt werden, doch dies hat gegenwärtig kein Empfehlungsniveau. Nicht selten wird es angesichts der kardiopulmonalen Dekompensation bei schweren COVID-19-Verläufen zur hypoxischen Enzephalopathie kommen. Dann steht neben der o.g. homöostasegerichteten Therapie und ggf. dem Einsatz von Levetiracetam, Valproat oder Piracetam gegen postanoxische Myoklonien v.a. die Prognoseabschätzung durch kombiniert Klinik, EEG, SSEP, CT und NSE im Vordergrund.

\section{Enzephalopathien bei COVID-19}

Die ersten Charakterisierungen allgemeiner COVID-19-Kohorten aus China boten auch Symptome, die mit Enzephalopathien $\mathrm{zu}$ vereinbaren waren, wie Fatigue (23-73\%) oder Übelkeit und Erbrechen (4-9\%; [35-38]). Studien, in denen gezielt nach neurologischen Symptomen gefahndet wurde, beschrieben bei Aufnahme oder im Verlauf Schwindel (17\%), Halluzinationen, Verwirrtheit, Dysexekutivstörungen (nach Intensivverlauf $36 \%$ ), Agitation (im Intensivverlauf $69 \%$ ), Vigilanzminderung (8-15\%), epileptische Anfälle (1\%), Ataxie (1\%), plötzliche neurologische Defizite (3\%), oder Pyramidenbahnzeichen (im Intensivverlauf 67\%; [39, 40]).

In einer Serie aus Strasbourg berichteten Helms et al. bei 58 Patienten mit schweren Verläufen (ARDS und Intensivbehandlung) unterschiedliche ZNS-Manifestationen, großteils während der Unterbrechung einer Analgosedierung, wie Delir oder kortikale Dysfunktionen. Paraklinisch zeigten 8 dieser Patienten eine diffuse Hirnfunktionsstörung im EEG, von 13 Patienten 11 Perfusionsstörungen (3-mal mit akuter zerebraler Ischämie) und 8 in der MRT ein leptomeningeales Enhancement. Die Liquoranalyse bei 7 Patienten war ohne Virusnachweis [41]. Die Autoren mutmaßten, dass die neurologischen Symptome Folgen einer übermäßigen Zytokinausschüttung oder der Intensivtherapie sind. Ein Zytokinsturm mag auch dem eindrucksvollen Fallbericht einer COVID-19-assoziierten akuten hämorrhagisch-nekrotisierenden Enzephalopathie zugrunde gelegen habe, die Poyiadji et al. bei einer Ende 50-jährigen Patientin in Detroit gefunden hatten. Nach $3 \mathrm{Ta}-$ gen Fieber, Husten und Verwirrtheit kam es zu einem schweren respiratorischen Versagen unter der Diagnose von COVID-19. Die CT zeigte bithalamische Hypodensitäten, die MRT bilaterale mesiotemporale und ausgeprägte thalamische Hyperintensitäten in der FLAIR-Wichtung, thalamische Hämorrhagien in der Suszeptibilitätswichtung sowie ein Ring-Enhancement nach KM-Gabe. Eine Behandlung mit IVIG wurde initiiert, der weitere Verlauf ist unbekannt [23]. Eine radiologische Serie er- 
Hier steht eine Anzeige.

Springer 
brachte mit Enzephalopathie kompatible MRT-Veränderungen wie Leukenzephalopathie mit konfluierenden T2-Hyperintensitäten bei 10/11 und Mikroblutungen bei 7/11 New Yorker COVID-19-Patienten mit persistierenden Bewusstseinsstörungen [42]. Im Fall eines 74-jährigen Patienten mit vorbestehendem Schlaganfall, M. Parkinson und COPD führte COVID-19 zu Kopfschmerz und Wesensänderung. Das EEG zeigte fokale Verlangsamungen und scharfe Wellen, im Wesentlichen im Bereich der alten ischämischen Läsion. Die Autoren schlossen angesichts einer unauffälligen Liquoranalyse auf eine Enzephalopathie und starteten eine Behandlung mit Hydroxychloroquin und Lopinavir/Ritonavir, der Ausgang ist nicht bekannt [43]. In einer Serie von 29 Intensivpatienten mit gesicherter COVID19 aus der deutschen PANDEMIC-Studie, die sämtlich lumbalpunktiert wurden, zeigten 12/29 ein enzephalopathisches klinisches Bild, während der Liquor in den meisten Fällen unauffällig war und in keinem Fall einen Virusnachweis per PCR zeigte [44]. Diese Publikationen legen nahe, dass eine Enzephalopathie im Rahmen von COVID-19, gerade bei schweren Verläufen, recht häufig vorkommt, dass die Präsentationen und Verläufe aber höchst heterogen sind. Eine belastbare Grundlage für spezifischere Therapieempfehlungen existiert noch nicht. Es müssen individuelle Behandlungen der Patienten auf Grundlage der o.g. Diagnostik erfolgen.

\subsection{Enzephalitis}

\section{Definition und Klassifikation}

Die akute Virusenzephalitis ist die direkte Infektion des Hirngewebes mit einem Virus. Das Virus kann dabei selbst durch lytische Replikationszyklen schädigend auf Hirnzellen wirken oder durch die zytotoxische Immunantwort des Wirtsorganismus. Daneben kann die Virusenzephalitis über die virusoder wirtsvermittelten Begleitreaktionen (erhöhte Hirntemperatur, Hirnödem, Elektrolyt- und Neurotransmitterdisbalancen u.v. m.) funktionell schädigend auf das Gehirn wirken. Oft sind auch die Hirnhäute mitbeteiligt, weshalb dann meist treffender von einer Meningoenzephalitis zu sprechen ist. Auch das Rückenmark kann isoliert oder zusätzlich betroffen sein, was als Myelitis oder Enzephalomyelitis bezeichnet wird. Die wichtigste Virusenzephalitis ist wegen ihres schweren, mitunter hämorrhagisch-nekrotischen Verlaufs und ihrer kausalen Behandelbarkeit die Herpes-simplex-Virus-Enzephalitis (HSVE). Neben den Herpesviren sind andere häufige Virusgruppen, die eine Enzephalitis hervorrufen können, Enteroviren, Paramyxoviren und Arboviren.

Auch Coronaviren rufen Enzephalitiden hervor, wie schon während der SARS-und MERS-Epidemien in klinischen und tierexperimentellen Studien nachgewiesen wurde [45]. Wege der Neuroinvasion, die für SARS-CoV-2 als relevant angesehen werden, sind hämatogen über oder entlang der Blut-HirnSchranke (BHS) oder über Blutzellen als Transporter („Trojaner"), lymphatisch, transneuronal bzw. transsynaptisch über Nervenverbindungen zur Riechschleimhaut, über Hirnnerven mit Verbindungen zum Nasen-Rachen-Raum oder Atemwegen sowie Nerven des Darmnervensystems [6, 34, 46, 47].

Eine akute Enzephalitis kann auch erregerunabhängig bestehen und wird dann gewöhnlich Autoimmunenzephalitis genannt. Es ist zwar prinzipiell denkbar, dass systemische Virusin- fektionen solche Autoimmunenzephalitiden triggern, auch verzögert postinfektiös. Ob dies in relevantem Ausmaß auch infolge einer Infektion mit SARS-CoV-2 auftreten kann, ist aktuell noch unklar.

\section{Diagnostik}

$\mathrm{Zu}$ Beginn der Diagnostik steht die Erfassung der klinischen Präsentation. Bei folgenden Symptomen sollte an eine Virusenzephalitis gedacht werden, mitunter - aber nicht zwingend - nach einer "grippalen“ Prodromalphase von 1-4 Tagen:

- Kopfschmerz, ohne oder mit nur geringer Nackensteifigkeit

- Fieber

- psychische Auffälligkeiten, Verwirrtheit, selten Halluzinationen

- qualitative oder quantitative Bewusstseinsstörungen

- fokale oder generalisierte epileptische Anfälle, ggf. Status epilepticus

- fokalneurologische Defizite (z. B. Sprachstörungen, Lähmungen, Koordinationsstörungen, Blickstörungen)

Die folgende Zusatzdiagnostik ist bei Verdacht auf eine Virusenzephalitis indiziert:

- Routinelabor mit Blutbild und Infektionsparametern

- Lumbalpunktion und Liquoranalyse (mit Zellzahl, Gesamteiweiß, Laktat, Immunglobulinen, oligoklonalen Banden) und Erregerdiagnostik (RT-PCR auf SARS-CoV-2)

- Magnetresonanztomographie (MRT)

- Elektroenzephalographie (EEG)

Das EEG ist so gut wie immer pathologisch, wobei die Veränderungen von eindeutigen Anfalls- oder Statusmustern und Herdbefunden bis zu recht unspezifischen Allgemeinveränderungen reichen. Das MRT kann normal ausfallen, lokales Hirnödem und/oder (multi-)fokale Kontrastmittelaufnahme zeigen. Der Nachweis der Enzephalitis gelingt dann meist über den Liquor, der oft eine leichte Erhöhung der Zellzahl auf 10-30/ $\mu$, eine geringe Eiweißvermehrung bis etwa $0,7 \mathrm{~g} / \mathrm{l}$ und eine nur geringe Laktaterhöhung zeigt, dazu ggf. eine intrathekale Immunglobulinsynthese. Der PCR-Nachweis des Virus im Liquor beweist die spezifische Enzephalitis, misslingt aber nicht selten trotz wiederholter Versuche auch bei direkter Virusinvasion.

Häufigere Differenzialdiagnosen der akuten Virusenzephalitis sind die Hirnvenen- und Sinusthrombose, Hirntumoren oder -metastasen sowie Psychosen oder Delir.

\section{Therapie}

Für viele akute Virusenzephalitiden steht keine kausale Therapie zur Verfügung, nennenswerte Ausnahmen bilden Aciclovir oder Foscarnet bei HSVE oder Varizella-Zoster-Virus(VZV)Enzephalitis. Potenzielle antivirale Medikamente gegen SARSCoV-2 befinden sich aktuell in der Erprobung. Für die Behandlung einer SARS-CoV-2-Enzephalitis wäre wichtig, dass diese BHS-gängig sind.

Die zusätzliche Therapie mittels Glukokortikoiden konnte bisher nicht als eindeutig vorteilhaft nachgewiesen werden. Die symptomatische Therapie besteht u.a. aus Kontrolle der allgemeinen Homöostase (Elektrolyte und Flüssigkeit), dem Einsatz von Analgetika und Antipyretika, der neuroleptischen oder antidepressiven Therapie von psychotischen Krankheitsanteilen und der antikonvulsiven Therapie epileptischer Anfälle. Bei schweren Verläufen ist eine supportive Intensivtherapie ange- 
bracht inklusive ggf. Intubation und Beatmung, Thromboseprophylaxe, Neuromonitoring, ggf. eskalierende Therapie von Hirnödem, erhöhtem intrakraniellem Druck und Status epilepticus.

\section{Zusammenfassung der wichtigsten (evidenzbasierten) Erkenntnisse}

Im Folgenden werden nur Arbeiten zusammengefasst, die COVID-19-assoziierte Enzephalitiden im Sinne der o.g. Definition berichteten, während solche, die zwar den Begriff Enzephalitis anführten, bei denen aber wohl eher eine Enzephalopathie vorlag, im Folgenden nicht besprochen werden.

Von COVID-19-Fallserien zu Symptomen, die prinzipiell für eine Enzephalitis suggestiv waren, sind insbesondere Studien $\mathrm{zu}$ nennen, in denen gezielt nach neurologischen Symptomen gefahndet wurde. Diese beschrieben bei Aufnahme oder im Verlauf (plötzliche) Geruchs- und Geschmacksstörungen (10-70\%), Kopfschmerzen (13\%), Schwindel (17\%), Halluzinationen, Verwirrtheit, Dysexekutivstörungen (nach Intensivverlauf $36 \%$ ), Agitation (im Intensivverlauf $69 \%$ ), Vigilanzminderung (8-15\%), Neuralgie (2\%), epileptische Anfälle (1\%), Ataxie (1\%), plötzliche neurologische Defizite (3\%) oder Pyramidenbahnzeichen (im Intensivverlauf $67 \%$ ), allerdings mehrheitlich ohne Liquoranalyse, sodass das Vorliegen einer akuten Virusenzephalitis nicht sicher beurteilt werden kann [39, 40, 48]. Die Fallserie (58 Patienten) von Helms et al. beinhaltete unter 7 lumbalpunktierten Patienten einen Patienten mit erhöhtem Liquorprotein und intrathekaler IgG-Produktion, sodass hier möglicherweise eine Enzephalitis vorlag [40].

Der Beweis des direkten Befalls des zentralen Nervensystems wurde wohl erstmalig bei einem japanischen Patienten mit Meningoenzephalitis geführt, bei dem nach einem fieberhaften Verlauf mit starker Müdigkeit über wenige Tage epileptische Anfälle aufgetreten waren. Der Patient entwickelte im Verlauf eine schwere Pneumonie. Die Liquoranalyse zeigte 12 mono-/polynukleäre Zellen/ $\mu$ l und erbrachte den Nachweis von SARS-CoV-2, während ein Rachenabstrich negativ ausgefallen war. In der MRT boten sich DWI-Hyperintensitäten der Ventrikelwand, FLAIR-Hyperintensitäten mesiotemporal und hippocampal. Der Patient wurde neben der pulmonal dominierten Intensivtherapie hinsichtlich seiner Enzephalitis unter anderem mit Aciclovir, später Favipiravir und Steroiden sowie dem Antikonvulsivum Levetiracetam behandelt. Der Ausgang der Behandlung bleibt unklar [49]. Ein weiterer Fall mit Meningoenzephalitis und Virusnachweis im Liquor soll im Ditan Hospital Beijing, China, gelungen sein, wurde aber nicht über PeerReview veröffentlicht. Der Fall eines 40-jährigen Patienten mit Fieber, Synkope und anschließenden enzephalitischen Symptomen zeigte nach nasopharyngealem positivem SARS-CoV-2Test zunächst einen negativen und später einen positiven Virusnachweis im Liquor. Unter Hydroxychloroquin besserten sich die Symptome, sodass er nach 12 Tagen neurologisch unauffällig war [50]. Am Mt Sinai Hospital New York erfolgte der autoptische Nachweis von SARS-CoV-2 im Frontallappen einer 74-jährigen Parkinson-Patientin, die mit Zunahme von Tremor und Gangstörung, Fieber sowie Verwirrtheit vorgestellt wurde und bei COVID-19-Diagnose innerhalb von 11 Tagen nach schwerem respiratorischem Verlauf verstorben war. Die neuropathologische Aufarbeitung zeigte nicht nur Viruspartikel in den Vakuolen von Neuronen, sondern auch Vesikel mit Virusmaterial in benachbarten Endothelzellen als möglichen Hinweis auf eine hämatogene Einwanderung [51]. Weitere neuropathologische Detektionen von SARS-CoV-2 in den Gehirnen verstorbener COVID-19-Patienten (8 von 22) wurden in einer Hamburger Serie berichtet [52]. Der kürzliche MRT-Fallbericht einer Patientin mit positivem nasopharyngealem SARSCoV-2-Nachweis und Anosmie zeigte transiente Signalauffälligkeiten im Bulbus olfactorius und Gyrus rectus als starken paraklinischen Hinweis auf eine transnasale Neuroinvasion [53]. Ohne zentralen Virusnachweis, aber doch mit Zeichen einer Enzephalitis waren 2 Fälle aus Lausanne: Eine 64-jährige, im Verlauf COVID-19-diagnostizierte Patientin entwickelte nach 5 Tagen mit grippalen Symptomen akut psychotische Symptome und tonisch-klonische Anfälle bis hin zum nichtkonvulsiven Status epilepticus. Klinisch standen im Weiteren Desorientiertheit, Perseverationen und Wahn im Vordergrund. Eine 67jährige Patientin hatte schon seit 17 Tagen COVID-19, als sie starken Kopfschmerz entwickelte, danach eine Bewusstseinstrübung und Verwirrtheit, Perseverationen, Aggressivität, $\mathrm{He}$ mianopsie und sensiblen Hemineglekt. In beiden Fällen war das MRT normal; der Liquor blieb ohne Virusnachweis, zeigte aber eine lymphozytäre Zellzahlerhöhung von 17 bzw. 26/ $\mu$ l und ein erhöhtes Gesamteiweiß, also Befunde einer Enzephalitis. Beide Patientinnen erholten sich unter supportiver konservativer Therapie [54]. Die Enzephalitis eines 60-jährigen COVID-19Patienten mit Fieber, Wesensänderung, Verwirrtheit und einem schweren akinetischen Syndrom zeigte sich durch eine anhaltende mäßige Pleozytose und Eiweißerhöhung im Liquor, allerdings ohne Virusdetektion. Auch inflammatorische Marker im Liquor wie IL-8, TNF- $\alpha$, und Betamikroglobulin waren erhöht nachweisbar, das EEG war auffällig, das MRT normal. Unter zunächst hochdosierter, später ausschleichender Steroidtherapie und Hydroxychloroquin erholte sich der Patient innerhalb von 11 Tagen, während wiederholte Lumbalpunktionen prolongiert eine entzündliche Liquorkonstellation zeigten [55]. 6 von 29 beatmeten intensivstationären türkischen COVID-19Patienten mit ZNS-Affektion boten teils MRT-Auffälligkeiten, teils Liquorauffälligkeiten (hohes Eiweiß), die als Autoimmunenzephalitiden gewertet wurden, da sich kein Virusnachweis im Liquor fand. Unter Plasmapheresebehandlung zeigten 5 von ihnen einen günstigen Verlauf [56]. In einer Serie von 29 Intensivpatienten mit COVID-19 und unterschiedlichen neurologischen Manifestationen aus der deutschen PANDEMIC-Studie, die sämtlich lumbalpunktiert wurden, fanden sich zwar bei 4/29 eine erhöhte Zellzahl, bei 5/29 ein deutlich erhöhtes Liquoreiweiß (also gestörte Schrankenfunktion) und bei 3/29 ein erhöhtes Liquorlaktat, also kombiniert entzündliche Veränderungen, aber in keinem Fall ein Virusnachweis per PCR im Liquor [44].

Diese Fallserien und -berichte demonstrieren zwar die prinzipielle Möglichkeit eines direkten ZNS-Befalls durch SARS$\mathrm{CoV}-2$, erlauben aber keine zuverlässige Aussage über Häufigkeit und Relevanz für den Verlauf. Angesichts der großen Zahl von Infektionsfällen weltweit scheint die Zahl der Publikationen zu akuten Virusenzephalitiden gering, sodass anzunehmen ist, dass die direkte im Gegensatz zur indirekten Affektion des ZNS wohl eher ein seltenes Ereignis ist. Allerdings können neurologische Manifestationen inklusive Enzephalitis leicht un- 
erkannt bleiben bei schwer betroffenen intensivpflichtigen und analgosedierten Patienten mit dominierender Atemstörung, sodass die Zahlen evtl. falsch-niedrig sind, zumal auch der ausbleibende Virusnachweis im Liquor nicht immer die spezifische Enzephalitis ausschließt.

Aktuell ist eine Empfehlung zur kausalen Therapie nicht möglich. Symptomatische bzw. supportive Therapiemaßnahmen bei akuter SARS-CoV-2-Enzephalitis sollten sich individuell am klinischen Befund und den Ergebnissen der o.g. Diagnostik orientieren.

\section{Zerebrovaskuläre Erkrankungen}

Bearbeitet von Götz Thomalla, Hamburg, und Christian Nolte, Berlin

\section{Definition und Klassifikation}

Die SARS-CoV-2-Pandemie betrifft direkt und indirekt die Versorgung zerebrovaskulärer Erkrankungen. Es wird diskutiert, dass eine SARS-CoV-2-Infektion mit dem vermehrten Auftreten von zerebrovaskulären Erkrankungen wie ischämischen Schlaganfällen und intrazerebralen Blutungen assoziiert sein könnte. Zahlreiche Berichte legen eine Verschlechterung der Versorgung von Patienten mit zerebrovaskulären Erkrankungen aufgrund der besonderen Inanspruchnahme der Gesundheitssysteme während der Pandemie dar. Auswirkungen auf die Versorgung sind direkt und indirekt durch Umverteilung von Ressourcen zugunsten von SARS-CoV-2-Infizierten und Schutzmaßnahmen für die Patienten und das versorgende Personal erkennbar. Sie betreffen das Handeln der Laien (z. B. Angst vor Ansteckung im Krankenhaus), den Transport ins Krankenhaus und die intrahospitale Notfallversorgung bis hin zur Rehabilitation.

\section{Epidemiologie/Datenlage}

\section{SARS-CoV-2 als Risikofaktor für einen Schlaganfall}

Verschiedene Fallserien berichten Raten ischämischer Schlaganfälle bei hospitalisierten COVID-19-Patienten zwischen 1,6 und $5 \%$. Im Einzelnen lagen die Zahlen von ischämischen Schlaganfällen bei 3 von $184(1,6 \%)$ in einer niederländischen Fallserie [57], 9 von 362 (2,5\%) in einer Fallserie aus Mailand, Italien [39], und 6 von $214(2,8 \%)$ [58] bzw. 11 von 221 (5\%) [59] in 2 Fallserien aus Wuhan, China. Die Rate zerebrovaskulärer Ereignisse war dabei höher bei Patienten mit schweren respiratorischen Verläufen, und Patienten mit zerebrovaskulären Ereignissen wiesen häufig klassische vaskuläre Risikofaktoren auf, wobei auch eine erhöhte Rate kryptogener Schlaganfälle berichtet ist. In einer retrospektiven Kohortenstudie an 2 New Yorker Krankenhäusern kamen die Autoren zu dem Schluss, dass Patienten mit SARS-CoV-2-Infektion ein höheres Risiko für das Auftreten eines akuten, ischämischen Schlaganfalls haben als Patienten mit Influenzainfektion [60]. Eine weitere Analyse zeigte eine Rate von 32/3556 (0,9\%) bildgebend nachgewiesenen Schlaganfällen bei hospitalisierten SARS-CoV-2Infizierten. Schlaganfallsymptome waren aber nur bei 14/3556 (0,4\%) der initiale Aufnahmegrund gewesen [61].

Insgesamt scheinen die Schlaganfallraten in diesen Fallserien damit in einem Bereich zu liegen, welcher für Patienten mit schweren Infektionserkrankungen nicht ungewöhnlich ist.
Ein Hinweis auf ein spezifisch erhöhtes Schlaganfallrisiko bei Infektion mit SARS-CoV-2 ergibt sich aus diesen Zahlen daher aktuell nicht. Denkbar ist eine solche Assoziation allerdings, und als mögliche Ursache werden eine Aktivierung des Gerinnungssystems, eine disseminierte intravasale Gerinnung sowie vaskuläre Komplikationen als Ausdruck schwerer sonstiger Organschäden diskutiert, wie sie auch bei anderen schweren Virusinfektionen bekannt sind. In der Studie aus Wuhan wiesen die Patienten mit schweren respiratorischen Verläufen insgesamt höhere D-Dimer-Spiegel auf, welche eine mögliche Verbindung zur erhöhten Schlaganfallrate bei diesen Patienten darstellen. Die höhere Schlaganfallrate bei schwerer betroffenen Patienten könnte allerdings auch einem Selektionsbias geschuldet sein, da es v. a. multimorbide Patienten mit kardiovaskulären Risikofaktoren sind, die schwere Verläufe von COVID-19 zeigen.

In einer Fallserie $(n=5)$ aus New York wurde eine Häufung junger Schlaganfallpatienten mit großem Gefäßverschluss berichtet, welche mittels Thrombektomie behandelt wurden [62]. Bemerkenswert an dieser Fallserie ist die Tatsache, dass die Patienten zumeist keine schweren respiratorischen Symptome zeigten. Weiterhin beunruhigend ist die Beobachtung, dass 4 dieser 5 Patienten sich mit ihren Schlaganfallsymptomen nur verzögert zur Behandlung im Krankenhaus vorstellten. Die Verzögerung wurde mit einer Angst vor Ansteckung im Krankenhaus erklärt. Es bleibt abzuwarten, ob dies nur eine zufällige lokale Häufung einer bestimmten Patientengruppe darstellt oder den Hinweis auf eine besondere Risikokonstellation. Zum Zeitpunkt der Recherche dieser Leitlinie hatte keine andere Arbeitsgruppe ähnliche Häufungen von jungen Patienten mit großen Gefäßverschlüssen und zeitgleicher SARS-CoV-2-Infektion beschrieben.

Auch das Auftreten intrazerebraler Blutungen bei Patienten mit COVID-19 ist berichtet [39], hier ist die Datenlage jedoch noch stärker begrenzt und lässt keine zuverlässige Einschätzung der Häufigkeit zu.

Patienten mit zerebrovaskulären Erkrankungen in der Anamnese haben ein höheres Risiko für einen schwereren Verlauf der COVID-19-Erkrankung. In einer Metaanalyse der verfügbaren Arbeiten zum Thema war ein Schlaganfall in der Vorgeschichte mit einem 2,5-fach erhöhten Risiko für einen schweren Erkrankungsverlauf und einem Trend zu höherer Mortalität assoziiert [63].

\section{Auswirkungen der SARS-CoV-2-Pandemie auf die Versorgung von Patienten mit Schlaganfall}

Die COVID-19-Pandemie hat weltweit Einfluss auf die Organisation der Schlaganfallversorgung. Hier spielen 2 Faktoren eine wesentliche Rolle: Zum einen wurden an vielen Orten Ressourcen der akuten Versorgung von Schlaganfallpatienten zugunsten der Versorgung von Patienten mit COVID-19 umverteilt. Diese Ressourcen fehlten in der Versorgung der Schlaganfallpatienten. Zum Zweiten ist zu beobachten, dass die Anzahl der in Krankenhäusern behandelten Schlaganfallpatienten im Verlauf der COVID-19-Pandemie an vielen Orten deutlich zurückging. So wurden in der Elsass-Region im März 2020 im Vergleich zum Vorjahr $40 \%$ weniger Alarmierungen wegen Schlaganfall, $41 \%$ weniger i.v. Thrombolysen und $33 \%$ weniger Behandlungen mit Thrombektomie beobachtet [64]. Ähnliche Zahlen 
Hier steht eine Anzeige.

Springer 
wurden aus Italien berichtet, wo die Zahl von hospitalisierten Schlaganfallpatienten um $50 \%$ und die der Thrombolysen um $25 \%$ sanken [65]. Auch aus China wurden eine Abnahme von Krankenhauseinweisungen wegen Schlaganfall um $40 \%$ und eine Abnahme der Thrombolysezahlen um $25 \%$ berichtet [66]. Als wesentliche Ursachen hierfür werden die Verunsicherung der Bevölkerung und die Angst von Patienten vor einer Infektion bei Behandlung im Krankenhaus angenommen.

\section{Diagnostik}

\section{Generell}

Die Versorgung von Patienten mit SARS-CoV-2 und zerebrovaskulären Erkrankungen sollte interdisziplinär mit allen beteiligten Abteilungen koordiniert werden, insbesondere mit COVID-Behandlern, der Abteilung für Radiologie und der Abteilung für Kardiologie [67].

Die Exposition gegenüber SARS-CoV-2-positiven Patienten muss sowohl für das Personal als auch für Mitpatienten minimiert werden. Dies kann bedeuten, dass das Pflegende-zu-Patienten-Verhältnis angepasst wird, telemedizinische Verfahren eingebunden werden, Besuchsmöglichkeiten begrenzt werden und ausreichendes Schutzmaterial zur Verfügung steht. Um Exposition zu vermeiden, muss Exposition bekannt sein. Alle Patienten sollten deshalb generell auf SARS-CoV-2 gescreent werden. Die Befundung des SARS-CoV-2-Screenings sollte zeitnah und prioritär erfolgen.

Anmerkung: Die Kernaussage „Bei jedem Schlaganfall sollte umgehend auf SARS-CoV-2 getestet werden“ fand in der Expertengruppe keine Zustimmung, $30 \%$.

\section{Patienten mit SARS-CoV-2-Infektion}

Bei Patienten mit SARS-CoV-2-Infektion sollten behandelnde ÄrztInnen nach neurologischen Komplikationen fragen und daran denken, dass zerebrovaskuläre Erkrankungen bei diesen Patienten nicht selten sind. Insbesondere Patienten mit Komorbiditäten stellen eine Risikogruppe für das Auftreten zerebrovaskulärer Komplikationen dar. Bei klinischen Hinweisen sollten unverzüglich eine neurologische Konsultation erfolgen und eine entsprechende bildgebende Diagnostik mittels CT oder MRT durchgeführt werden. Es ist vorteilhaft, ein CT-Gerät speziell und ausschließlich für die Diagnostik von Patienten mit SARS-CoV-2-Infektion vorzuhalten, um Ansteckungsmöglichkeiten $\mathrm{zu}$ minimieren.

\section{Patienten mit zerebrovaskulärer Erkrankung und COVID-19}

Die entsprechende Leitlinie zur Diagnostik bei zerebrovaskulären Erkrankungen (Diagnostik akuter zerebrovaskulärer Erkrankungen, AWMF-Registernummer 030/117) hat ihre Gültigkeit auch für Patienten mit COVID-19-Infektion (u. a. zerebrale Bildgebung, Neurosonographie, kardiale Diagnostik, EKG inkl. Langzeit-EKG-Monitoring).

Um die Ansteckungsgefahr für das versorgende Personal zu begrenzen, sollte die Personalfluktuation begrenzt werden (z.B. ein festes Stroke-COVID-Team). Hygienestandards sollten eine angemessene Schutzkleidung beinhalten. Patienten mit COVID-19 können, sofern dies toleriert wird, eine Mund-NaseBedeckung tragen. Um die Übertragung auf andere Patienten noch besser zu verhindern, sollten sie isoliert werden. Es kön- nen Stationsbereiche für Patienten mit zerebrovaskulärer Erkrankung und COVID-19 ausgewiesen und für diese Patienten reserviert werden.

\section{Patienten mit zerebrovaskulären Erkrankungen ohne COVID-19}

Patienten mit zerebrovaskulären Erkrankungen ohne (bekannte) COVID-19-Infektion sollten auf SARS-CoV-2 gescreent werden, um eine Infektion frühzeitig $\mathrm{zu}$ erkennen und Isolationsmaßnahmen ergreifen $\mathrm{zu}$ können. Der Einsatz von Telemedizin kann das Infektionsrisiko durch Reduktion von Transporten verringern.

\section{Therapie}

\section{Akuttherapie}

Die Leitlinie der DGN zur Akuttherapie von Patienten mit akutem ischämischem Schlaganfall hat auch bei Patienten mit SARS-CoV-2-Infektion Gültigkeit (Akuttherapie des ischämischen Schlaganfalls - Rekanalisierende Therapie [Ergänzung 2015], AWMF-Registernummer 030/140). Patienten sollen eine Akutbehandlung mit intravenöser Thrombolyse oder Thrombektomie erhalten, sofern diese indiziert ist.

\section{Periinterventionelles Management bei Thrombektomie}

Die Akutbehandlung des schweren Schlaganfalls muss lückenlos unter Schutzmaßnahmen erfolgen. Dies gilt insbesondere für die Thrombektomie in der Zusammenarbeit von Neurologen, interventionellen Neuroradiologen, Anästhesisten und Pflegekräften wegen der Nähe zum Patienten und der Gefahr der Aerosolverbreitung. Mehrere mit diesem Setting betraute Fachgesellschaften haben hierzu Empfehlungen herausgegeben. Dazu zählen die Einordnung jedes Patienten als prinzipiell COVID-19-verdächtig mit der Notwendigkeit umgehender Testung, die Bevorzugung einer Intubationsnarkose (zur Vorbeugung einer möglichen unkontrollierten Notfallintubation während der Intervention), die videolaryngoskopische Intubation in Räumlichkeiten mit Absaugung, die Reduktion der Beteiligten auf die wirklich notwendige Anzahl und die Verwendung von persönlichem Schutz- und Barrierematerial für Patient und Behandler [68-72].

\section{Sekundärprävention}

Die Leitlinien der DGN zur Sekundärprävention bei Patienten mit ischämischem Schlaganfall haben auch bei Patienten mit SARS-CoV-2-Infektion Gültigkeit. Dies betrifft sowohl die medikamentöse Sekundärprävention als auch die nicht medikamentösen Maßnahmen. Bei Patienten mit schwerem Verlauf einer COVID-19-Erkrankung sollte der Beginn der medikamentösen Sekundärprävention, z. B. mit oraler Antikoagulation, im Gesamtkontext der Situation des Patienten und in Abstimmung mit den behandelnden Kollegen der Infektiologie oder Intensivmedizin festgelegt werden.

Der Zeitpunkt für operative oder interventionelle Maßnahmen der Sekundärprävention wie einer Thrombendarteriektomie der A. carotis oder dem Verschluss eines persistierenden Foramen ovale sollte ebenfalls im Gesamtkontext der Situation des Patienten mit den jeweils die Maßnahmen durchführenden Kollegen festgelegt werden. Hier kann es in der Risikoabwä- 
gung sinnvoll sein, zunächst abzuwarten, bis der Patient die Infektion mit SARS-CoV-2 überstanden hat und kein Virus im Rachenabstrich mehr nachweisbar ist.

\section{Versorgungskoordination}

Patienten, die mit akutem Schlaganfall oder intrazerebraler Blutung ins Krankenhaus kommen und bei denen der Nachweis von SARS-CoV-2 erfolgt ist oder der Verdacht auf eine Infektion besteht, müssen umgehend isoliert werden. Die Entscheidung, ob Patienten auf einer neurologischen Stroke-Unit oder auf einer auf die Versorgung von Patienten mit COVID19 ausgelegten Station mit entsprechender Möglichkeit zum Monitoring behandelt werden sollen, muss im Einzelfall in Abhängigkeit von den Gegebenheiten des Krankenhauses (z. B. Möglichkeit zu und Erfahrung mit Isolation von Patienten mit SARS-CoV-2-Infektion auf der Stroke-Unit) und der klinischen Situation des Patienten getroffen werden.

Die COVID-19-Pandemie und die damit einhergehenden Schutzmaßnahmen für die Bevölkerung allgemein und in Krankenhäusern im Besonderen dürfen nicht zu einer schlechteren Versorgung von Schlaganfallpatienten führen. Schlaganfall ist unverändert eine Erkrankung mit häufig dramatischen Folgen und eine der Hauptursachen für bleibende Behinderung oder Tod. Bei aller notwendigen Ausrichtung des Gesundheitssystems auf die Versorgung von COVID-19-Patienten muss auch weiterhin eine optimale Organisation der Versorgung von Schlaganfallpatienten gewährleistet werden. Kliniken müssen durch entsprechende organisatorische Maßnahmen sicherstellen, dass sie auch unter den besonderen Bedingungen der COVID-19-Pandemie mit entsprechend notwendigen Schutzund Hygienemaßnahmen die adäquate Versorgung von $\mathrm{Pa}$ tienten mit zerebrovaskulären Erkrankungen gewährleisten können.

\section{Zusammenfassung}

Die aktuelle Pandemie des neuen Coronavirus SARS-CoV-2 hat Auswirkungen auf alle Bereiche der Medizin und betrifft direkt und indirekt auch die Versorgung zerebrovaskulärer Erkrankungen. Ischämische Schlaganfälle und seltener auch intrazerebrale Blutungen kommen bei Patienten mit COVID-19-Erkrankung vor und sind mit einem schwereren Verlauf der Erkrankung assoziiert. Die behandelnden ÄrztInnen von COVID-19Patienten sollten mögliche zerebrovaskuläre Komplikationen erkennen können und ggf. unverzüglich die notwendige Diagnostik veranlassen. Eine nachgewiesene Infektion mit SARSCoV-2 oder der Verdacht auf eine solche dürfen nicht dazu führen, dass solche Patienten mit akutem Schlaganfall schlechter behandelt werden als andere Schlaganfallpatienten. Unter Einhaltung der entsprechenden Hygienemaßnahmen müssen sie die gleiche Akutdiagnostik und Akutbehandlung erhalten wie alle Schlaganfallpatienten. Mit Sorge lässt sich beobachten, dass weltweit die Anzahl der Patienten, die wegen eines Schlaganfalls im Krankenhaus behandelt werden, unter der COVID19-Pandemie zurückgegangenen ist. Es ist anzunehmen, dass dieser Rückgang sich nur auf hospitalisierte Schlaganfallpatienten bezieht und nicht auf die wahre Inzidenz zerebrovaskulärer Ereignisse und dass im Umkehrschluss viele Patienten in der Pandemie keine adäquate Akuttherapie, Diagnostik, Sekundärprävention und Rehabilitation erhalten. Es ist in der Pandemie eine wichtige Aufgabe für alle in der Schlaganfallversorgung tätigen ÄrztInnen, die hohe Qualität der Versorgung zerebrovaskulärer Erkrankungen in Deutschland auch unter den aktuell erschwerten Bedingungen bestmöglich aufrechtzuerhalten.

\section{Epileptische Anfälle und Epilepsie bei Erwachsenen}

Bearbeitet von Felix Rosenow, Frankfurt/Main

\section{Definition und Klassifikation}

2 klinische Situationen sind zu unterscheiden:

1. das erstmalige Auftreten von Anfällen bei COVID-19-Patienten und

2. das Auftreten einer COVID-19-Erkrankung bei einem Patienten mit bekannter Epilepsie (Prävalenz 0,6-0,7 \% der Bevölkerung).

Wenn während einer COVID-19-Erkrankung epileptische Anfälle auftreten, handelt es sich:

A.entweder um akut symptomatische Anfälle in Rahmen einer primären ZNS-Mitbeteiligung durch SARS-CoV-2 im Sinne einer Meningoenzephalitis oder auf dem Boden einer sekundären ZNS-Schädigung, z.B. bei COVID-19-assoziiertem Schlaganfall oder ICB (z.B. unter ECMO-Therapie). Akut symptomatische Anfälle sind definiert als epileptische Anfälle, die innerhalb von 7 Tagen nach einer akuten Hirnschädigung auftreten [73]. Bei Meningoenzephalitiden kann dieser Zeitraum länger sein, da die Erkrankung über längere Zeit aktiv (akut) bleiben kann;

B. oder es kommt gelegentlich vor, dass bei einer vorbestehenden Epilepsie anderer Ätiologie im Rahmen einer COVID-19-Erkrankung Anfallsrezidive oder -häufungen auftreten [74-76]. Beides scheint nach der bislang vorliegenden Literatur aber relativ selten $\mathrm{zu}$ sein. Lu et al. berichteten im April 2020 in Epilepsia Daten einer Kohorte von 300 schwer erkrankten COVID-19-Patienten und beobachteten keine akuten symptomatischen Anfälle [77, 78] In einer weiteren Untersuchung an 214 in Wuhan, China, stationär behandelten, an COVID-19 erkrankten Patienten (41\% davon nach respiratorischen Kriterien schwer) hatte ein Patient (0,5\%) einen akut symptomatischen Anfall erlitten [39]. Selten können diese Anfälle auch als Status epilepticus auftreten [79].

Aus der letzten SARS-Epidemie ist zudem bekannt, dass $\mathrm{Pa}$ tienten mit einer chronischen Epilepsie z.T. verminderten $\mathrm{Zu}$ gang zu Ärzten und Medikamenten haben und dadurch Medikamentenentzugsanfälle erleiden können [80]. Deswegen ist bei Patienten mit vorbestehender Epilepsie darauf $\mathrm{zu}$ achten, dass stets Zugang zur ambulanten neurologischen Versorgung besteht und dass ausreichend und rechtzeitig Antiepileptika verordnet werden, damit es nicht zu Versorgungsengpässen kommt [75].

\section{Diagnostik}

Die Diagnostik entspricht derjenigen, welche bei einem ersten Anfall oder einem Status epilepticus nach den relevanten DGNLeitlinien erfolgt.

Anamnese und Fremdanamnese: Es ist zu klären, ob vor Auftreten der COVID-19-Erkrankung bereits epileptische Anfälle aufgetreten sind bzw. ob eine chronische Epilepsie bestand und ggf. welches Syndrom vorlag. Zudem ist zu klären, ob Risi- 
kofaktoren für eine Epilepsie vorliegen und welche Vorerkrankungen und Begleitmedikationen bestehen.

EEG: Bei unklarer Bewusstseinsstörung oder V.a. aufgetretene epileptische Anfälle ist die Durchführung eines EEG indiziert. Bei Patienten mit V.a. oder nachgewiesener COVID-19Erkrankung sollte von der Durchführung der Hyperventilation abgesehen werden, um die Aerosolproduktion gering zu halten (Personalschutz) bzw. bei schwer betroffenen Patienten diese nicht zu destabilisieren (Patientenschutz). Gesucht wird nach generalisierten oder regionalen Verlangsamungen, Herdbefunden, epilepsietypischen Potenzialen und Anfallsmustern. Das EEG oder ein EEG-Monitoring können auch zur Therapiekontrolle eingesetzt werden. Dies ist besonders bei nichtkonvulsiven Status epileptici sinnvoll.

Bildgebung: Diese dient dem Nachweis epileptogener Läsionen und von Zeichen erhöhten intrakraniellen Drucks, z. B. bei Enzephalitis, Hirnblutung oder akutem ischämischem Schlaganfall. In der Akutsituation wird üblicherweise eine cCT durchgeführt werden. Ist dies nicht ausreichend, so empfiehlt sich dringlich die Durchführung einer MRT, da diese Methode sensitiver beim Nachweis epileptogener Läsionen und Prozesse ist.

Laboruntersuchungen: Neben den bei COVID-19 erforderlichen Untersuchungen dient dies dem Nachweis und der Serumkonzentration von Antiepileptika (bei vorbekannter Epilepsie), dem Ausschluss anderer Ursachen für akut symptomatische Anfälle wie z.B. Elektrolytentgleisungen oder Intoxikationen [73]. Einzelheiten sind auch den beiden relevanten Leitlinien $\mathrm{zu}$ entnehmen.

Liquoruntersuchungen: Wenn Anfälle im Rahmen einer COVID-19-Infektion auftreten, muss durch Liquorentnahme eine Meningoenzephalitis als Ursache ausgeschlossen oder bestätigt werden. Dabei sollte auch nach SARS-CoV-2-RNA gesucht werden $[78,81]$.

\section{Therapie}

Bei akutsymptomatischen Anfällen und Status epilepticus erfolgt die antiepileptische Therapie entsprechend den beiden relevanten DGN-Leitlinien. Beim Status wird initial in aller Regel die ausreichende Dosis eines Benzodiazepins gegeben. Bei einzelnen Anfällen mit vollständiger anschließender Erholung ist die Therapie mit einem rasch und breit wirksamen Antiepileptikum p.o. oder auch i.v. in der Regel ausreichend. Daneben stellt die Therapie der anfallsauslösenden Grunderkrankung (sofern verfügbar) die 2 . Therapiesäule dar.

Im Verlauf der antiepileptischen Therapie bzw. bei vorbestehender Epilepsie mit Anfallszunahme sind v. a. die Interaktionen von Antiepileptika mit COVID-19-Medikamenten zu beachten [75]. Eine Auflistung der möglichen Interaktionen findet sich z. B. auf der Webseite der DGfE und der „University of Liverpool“" (www.covid19-druginteractions.org).

\section{Versorgungskoordination}

Die Versorgungkoordination erfolgt wie beim ersten Anfall oder Status epilepticus (SE). Die Erstversorgung erfolgt durch den Rettungsassistenten oder Notarzt, die weitere stationäre Versorgung in einer neurologischen oder zentralen Notaufnahme durch den zuständigen neurologischen ärztlichen Dienst (ÄD). Bei V.a. COVID-19-Infektion werden betroffene Patienten in der Regel räumlich isoliert und durch den zuständigen oder hinzugezogenen neurologischen $\ddot{\mathrm{AD}}$ versorgt bzw. in einem multidisziplinären Behandlungsteam mitversorgt.

\section{Störungen der Chemosensorik: Anosmie, Ageusie}

Bearbeitet von Stefan Isenmann, Moers, und Thomas Hummel, Dresden

\section{Definition und Klassifikation}

Bei den Riechstörungen werden Hyposmie (vermindertes Riechvermögen) und Anosmie differenziert, wobei die komplette Anosmie den vollständigen Verlust des Riechvermögens bezeichnet, wohingegen eine funktionelle Anosmie eine ausgeprägte Einschränkung des Riechvermögens bezeichnet, bei der eine geringe, allerdings nicht alltagsrelevante Restwahrnehmung noch bestehen kann. Als Parosmien (früher „Kakosmien“) werden veränderte Wahrnehmungen von Gerüchen bezeichnet, als Phantosmien Wahrnehmung von Gerüchen ohne adäquate Reizquelle („Geruchshalluzinationen“). Als Ageusie wird ein völliger Verlust des Geschmacksinns bezeichnet, Hypogeusie bezeichnet eine Minderung desselben [82].

Der Riechsinn erfüllt eine Reihe sehr grundlegender Funktionen, die im Alltag häufig nur un- oder unterbewusst wahrgenommen werden [83].

Hierzu zählen insbesondere:

- Nahrungsaufnahme (Aroma, Appetitanregung), aber auch Warnfunktion (Verdorbenes, Gift)

- Wahrnehmung von Gefahren (z. B. Brandgeruch, Verwesung)

- interpersonelle und soziale Kommunikation (z. B. Körpergerüche).

Bei der komplexen Geruchs- und Geschmackswahrnehmung beim Essen und Trinken wirken Eindrücke aus 3 Sinneskanälen zusammen:

- olfaktorisches System (N. olfactorius), mehrere Millionen olfaktorische Rezeptorneuronen, die jeweils 1 von beim Menschen etwa 380 funktionellen Rezeptoren exprimieren [84-86] - gustatorisches System (N. facialis, N. glossopharyngeus, N. vagus), 5 Geschmacksqualitäten: süß, sauer, salzig, bitter, umami (z.B. Glutamat)

- N. trigeminus (Schärfe von z. B. Meerrettich, Senf; Konsistenz, Prickeln von Kohlensäure, Temperatur)

Riecheindrücke sind komplex, weil durch das Ansprechen verschiedener Rezeptoren eine Vielzahl unterschiedlicher Erregungsmuster im Bulbus olfactorius entsteht, die die Qualität von Düften kodieren. Riecheindrücke entstehen, indem Gerüche entweder beim Schnüffeln von außen zur Riechschleimhaut gelangen oder beim Essen und Trinken über den Rachen (retronasal). Hierdurch kann die Diskriminierung von Störungen des Riechens bzw. Schmeckens unscharf und schwierig sein.

Wichtige Ursachen einer Riechstörung sind entzündliche Erkrankungen der Nase wie die chronische Rhinosinusitis, neurodegenerative Erkrankungen, insbesondere M. Parkinson und Demenzen, sowie frontoorbitale Schädel-Hirn-Verletzungen. Riechstörungen in der Folge viraler (grippaler) Infekte der oberen Atemwege sind als postinfektiöse Anosmien seit Langem bekannt [87]. Postinfektiöse Anosmien sind nach Infektionen mit einer Reihe von Erkältungsviren, u.a. Adenound Rhinoviren, beschrieben [88-90].

Häufig sind diese Anosmien mit nasalen Symptomen vergesellschaftet: Schnupfen, Niesen, Rhinorrhö, Kongestion, Ob- 
Hier steht eine Anzeige.

Springer 


\section{Infobox Relevante weitere Links}

- https://www.lice.it/pdf/Antiepileptic_drugs_interactions_in_ COVID-19.pdf

- www.ilae.org/patient-care/covid-19-and-epilepsy

- www.aesnet.org/about_aes/position_statements/covid-19

- www.covid19-druginteractions.org

struktion. Eine Riechstörung bis zur Anosmie im Rahmen von viralen Atemwegsinfekten kann insofern reine Begleiterscheinung des Infekts mit einer mechanischen Verlegung der Atemwege sein. Pathophysiologisch kommen auch ein direkter Virusbefall der Sinneszellen mit resultierender Funktionsstörung und Apoptose sowie mögliche Folgen einer Immunreaktion in Frage.

Bei SARS-CoV-2 geht die Riechstörung - anders als bei vielen anderen respiratorischen Viren - überwiegend nicht mit Symptomen einer Rhinitis einher, sodass v. a. direkte schädigende Effekte des Virus auf das olfaktorische System diskutiert werden.

Coronaviren sind neurotrop und können neuroinvasiv sein $[45,91,92]$. ACE2 ist ein funktioneller Rezeptor für SARSCoV-1 [93]. In ACE2-transgenen Mäusen gelangt SARS-CoV-1 über die Riechbahn in das Gehirn und führt dort zu neuronalem Zelltod ohne relevante Entzündungsreaktion sowie zum Tod der Tiere [94]. Allerdings gibt es nur einen Fallbericht einer anhaltenden Anosmie bei einer jungen Frau nach SARS durch SARS-CoV-1 [95].

Auch SARS-CoV-2 gelangt über ACE2 in Zellen und scheint ähnlich neurotrop zu sein $[34,96,97]$. So kann möglicherweise eine Riechstörung bei COVID-19 Ausdruck einer direkten Schädigung durch SARS-CoV-2 auf Ebene des Riechepithels oder der Riechbahn sein [98] - oder aber eine weiterreichende Invasion des ZNS über die Riechbahn in das ZNS anzeigen, wie das für andere Viren bereits gezeigt wurde [99]. SARS-CoV-2 wurde in Autopsien im menschlichen Gehirn nachgewiesen [100]. Daten über eine mögliche längerfristige Persistenz im ZNS und ggf. längerfristige Folgen beim Menschen liegen bislang nicht vor.

\section{Störungen der Chemosensorik bei COVID-19}

Die ersten Berichte von COVID-Patienten beschrieben ab Anfang 2020 zunächst schwer betroffene, meist intensiv- und beatmungspflichtige Patienten aus China [101-103], später aus Italien [104] und Deutschland [105]. Erstmals beschrieben Mao et al. neurologische Symptome bei stationären COVID-19-Patienten, darunter bei 11/214 Patienten (5\%) Riechstörungen [39]. Mildere Erkrankungsverläufe rückten erst im März 2020 in den Blickpunkt.

Aus dem Iran wurde eine Serie mit 10.069 ambulanten Patienten berichtet, von denen $48 \%$ eine Anosmie angaben, davon $76 \%$ mit plötzlichem Beginn. 83\% der Patienten mit Anosmie gaben auch eine Ageusie an [106]. Ab Anfang April folgte eine Vielzahl von Berichten über Riech- und Schmeckstörungen bei COVID-19 (Tab. 1 aus [107]). Die Arbeiten sind ausgesprochen heterogen, in der Pandemie wurden z. T. noch vorläufige und widersprüchliche Daten sehr rasch publiziert. Auch wenn Details daher nicht als abschließend geklärt angesehen werden können, zeichnen sich einige wesentliche Punkte aktuell ab:
- Riech- und Schmeckstörungen sind bei COVID-19 häufig.

- Riech- und Schmeckstörungen bei COVID-19 kommen insbesondere bei leichteren Verlaufsformen vor; häufiger bei vormals Gesunden, bei jungen Menschen; bei Frauen häufiger als bei Männern.

- Riech- und Schmeckstörungen können erstes (und seltener einziges) Symptom einer COVID-19-Erkrankung sein.

- Ob eine pathophysiologisch eigenständige gustatorische Störung zusätzlich zu einer Riechstörung oder sogar unabhängig davon auftreten kann, ist noch strittig. Einige Autoren vertreten die Ansicht, dass es sich vielmehr um den subjektiven Eindruck einer (zusätzlichen) Schmeckstörung handeln dürfte, da bei einer Anosmie neben dem Riechen durch Schnüffeln auch die retronasale Olfaktion bei der Nahrungsaufnahme beeinträchtigt bzw. ausgefallen ist [108].

- Riechstörungen bei COVID-19 sind häufig nicht mit Symptomen einer Rhinitis (Schnupfen, Niesen, Rhinorrhö, Kongestion, Obstruktion) vergesellschaftet und unterscheiden sich insofern phänomenologisch und womöglich auch pathophysiologisch von anderen postviralen Riechstörungen.

- Riechstörungen bei COVID-19 sind häufig deutlich ausgeprägt. Parosmien können initial bzw. im Krankheitsverlauf und der Regenerationsphase vorkommen; Phantosmien sind seltener.

\section{Diagnostik}

In der Pandemie hat ein plötzlicher Riechverlust bei Patienten ohne nasale Obstruktion eine Spezifität von $97 \%$ und eine Sensitivität von $65 \%$ für COVID-19 [109].

Damit sollte eine während der Pandemie neu auftretende Riechstörung/Anosmie (mit oder ohne subjektiven Eindruck einer zusätzlichen gustatorischen Störung) unmittelbar Anlass geben zu:

- Selbstisolation/Quarantäne

- Testung auf SARS-CoV-2 (über telefonische Kontaktaufnahme mit Hausarzt/Gesundheitsamt)

- Verwendung persönlicher Schutzausrüstung bei professionellem Kontakt mit Betroffenen

Aufgrund der epidemiologischen Bedeutung für die Kontrolle der Ausbreitung von SARS-CoV-2 während der Pandemie sind Anamnese, Kontaktverfolgung, Schutzmaßnahmen für Kontaktpersonen von besonderer Bedeutung.

Eine ausschließliche Selbstauskunft hinsichtlich Riech- oder Schmeckstörung korreliert nur eingeschränkt mit objektiven Befunden [110]. Standardisierte Fragebögen können die Diagnosesicherheit erhöhen [111]. Goldstandard ist die psychophysische Testung, bei der für die Riechfunktion getestet werden: Riechschwelle (z. B. mit Rosenduftverdünnungsreihe), Geruchsdiskrimination und Riechstoffidentifikation (z.B. mit Sniffin' Sticks). Für das Geschmacksempfinden werden die Qualitäten süß, sauer, salzig, bitter getestet. Einschlägige Untersuchungen hierzu sind in Tab. 3 aus [107] zusammengestellt.

Aufgrund des Expositionsrisikos für den Untersucher einerseits und eher geringer individueller Relevanz für die Patienten andererseits wird man allerdings in der Akutsituation in der Regel auf die psychophysische chemosensorische Testung verzichten bzw. selbstständig durchführbare Wegwerftestsysteme einsetzen, wie z. B. den Duftidentifikationstest UPSIT-Test [112, 113]. Sofern dies (z. B. aus epidemiologischen Gründen und in 
Situationen, in denen nicht unmittelbar mittels Rachenabstrich und RT-PCR auf SARS-CoV-2 getestet werden kann) erforderlich scheint, ist eine Selbsttestung der Patienten in häuslicher Quarantäne mit haushaltsüblichen Riechstoffen und mit nach Anleitung selbst hergestellten Schmecklösungen möglich [114, $115]$.

\section{Bildgebung}

Zwischenzeitlich mehren sich Berichte, die entweder eine Schleimhautschwellung mit Sekret in der Olfaktoriusrinne (cCT, cMRT) oder Signalveränderungen in Bulbus und/oder N. olfactorius (MRT) nachweisen. In Einzelfällen wurden auch Veränderungen im orbitofrontalen Kortex beschrieben (Tab. 4 aus [107]). Die Relevanz dieser Befunde kann derzeit noch nicht abschließend bewertet werden.

\section{Verlauf und Therapie}

Der Verlauf von Riech- und Schmeckstörungen bei COVID19 wird als generell günstig angesehen: Ein Großteil der Patienten berichtet eine vollständige bzw. weitgehende Besserung binnen 2-3 Wochen. In ca. 10-20\% der Fälle bleiben relevante Einschränkungen zurück (Tab. 2 aus [107]). Damit ist die Prognose wahrscheinlich günstiger als bei postviralen Riechstörungen anderer Ätiologie. Eine Umfrage beschrieb bei $80 \%$ der Patienten nach einer postviralen Riechstörung (ohne weitere Differenzierung der Ätiologie) eine gute Besserung innerhalb 1 Jahres [116]; andere Studien, in denen das Riechvermögen gemessen wurde, berichteten über eine Besserung im etwa gleichen Zeitraum bei postviralen Riechstörungen von ca. $30 \%$ [117].

Sofern eine Riechstörung im Rahmen einer COVID-19Erkrankung sich nicht binnen 4 Wochen wieder weitgehend zurückgebildet hat, sollten eine neurologische und HNO-ärztliche Vorstellung erfolgen, mit Anamnese (u. a. auch hinsichtlich konkurrierender/alternativer Ursachen) und Untersuchung, i.d.R. nach negativem Rachenabstrich. In diesem Rahmen erfolgen eine psychophysische Riech- und Schmecktestung, ergänzt durch Labordiagnostik, Bildgebung und Endoskopie. Sofern eine Riechstörung länger anhält, kann eine Therapie mit konsequentem, strukturiertem „Riechtraining“ versucht werden. Klassischerweise werden hierzu eingesetzt: Rose, Zitrone, Eukalyptus, Gewürznelke [118].

Siehe auch gesonderte Online-Tabellen „Störungen der Chemosensorik bei COVID-19“ [107].

\section{Neuromuskuläre Erkrankungen \\ Bearbeitet von Benedikt Schoser, München}

\section{Definition und Klassifikation}

2 unterschiedliche Problembereiche müssen differenziert werden:

- die Manifestation einer SARS-CoV-2-Infektion/COVID-19Erkrankung am peripheren Nervensystem oder der Muskulatur

und

- die sekundäre Verschlechterung einer präexistenten neuromuskulären Erkrankung durch eine SARS-CoV-2-Infektion/ COVID-19-Erkrankung.
Myalgien, Fatigue und HyperCKämie stellen als Trias die häufigste Form (40-70\%) einer Skelettmuskelaffektion in COVID19-Kohorten dar [39, 119-122]. Eine Rhabdomyolyse war bei 0,2\% und erhöhte CK-Werte waren bei 13,7\% der 1099 COVID-19-Patienten nachweisbar [120, 123]. Bei bis zu $30 \%$ der Erkrankten findet sich die CK-Erhöhung im Median bereits nach 1-2 Tagen [39, 119-122]. Nur ein Fallbericht zum Auftreten einer möglichen Primärmanifestation als Myositis im Rahmen einer SARS-CoV-2-Infektion ist publiziert [124].

Sekundäre Verschlechterungen neuromuskulärer Erkrankungen sind nur für die amyotrophe Lateralsklerose (ALS) und die Myasthenia gravis publiziert [125].

In Italien wurden 3 Patienten mit Erstmanifestation einer azetylcholinrezeptorantikörperpositiven Myasthenia gravis 5-7 Tage nach Beginn der fieberhaften SARS-CoV-2-Infektion beobachtet [126].

Für das periphere Nervensystem sind Fallberichte und kleinere Fallserien $\mathrm{zu}$ SARS-CoV-2-getriggertem GuillainBarré-Syndrom (GBS) publiziert [19, 127, 128]. Innerhalb von 5-10 Tagen nach Symptombeginn von COVID-19 kann sich ein GBS entwickeln. Ein Teil dieser Patienten muss maschinell beatmet werden (siehe auch Abschn. 1.2). Zusätzlich sind wenige Patienten mit Miller Fisher-Syndrom (MFS) oder mit einer Ophthalmoparese berichtet [120, 129]. Zur chronischen inflammatorischen demyelinisierenden Polyneuropathie (CIDP) gibt es keine gesicherten Erkenntnisse in Bezug auf SARSCoV-2/COVID-19 [125].

Eine intensivmedizinpflichtige COVID-19-Erkrankung mit invasiver Beatmung kann zur sog. ICUAW („ICU-acquired weakness" [ICU: Intensivstation]), einem Krankheitsbild, bei dem die CIP („critical illness polyneuropathy“) und die CIM („critical illness myopathy“) ineinandergreifen, führen [130]. Bei intensivpflichtigen COVID-19-Patienten treten sehr häufig frühmotorische Defizite auf, die auf eine CIP und CIM zurückzuführen sind. Die ICUAW-Inzidenz nimmt mit der Schwere und Dauer der intensivpflichtigen Erkrankung zu und verstärkt sich durch Sepsis, Multiorganversagen, Hyperglykämie, parenterale Ernährung und bestimmte Medikamente (Sedativa, Antibiotika, Kortikosteroide, Muskelrelaxanzien). Das klinische Bild ist geprägt durch die Schwäche und Atrophie der gesamten Muskulatur, inklusive der Atemmuskulatur, und Empfindungsstörungen [131-134].

\section{Diagnostik}

Bei ambulanten Patienten sollte unter entsprechenden Hygienemaßnahmen die Standarddiagnostik neuromuskulärer Erkrankungen (Anamnese, klinische Untersuchung, EMG/NLG, Lungenfunktionsprüfung, Kreatinkinasebestimmung, ggf. LP, ggf. MRT der Muskulatur, ggf. Muskelbiopsie) durchgeführt werden. Auf Intensivstationen kann ebenfalls ein Bedside-EMG unter Beachtung der Hygienemaßnahmen durchgeführt werden. Eine Magnetresonanztomographie der Muskulatur ist aufgrund des hohen Aufwands, verbunden mit einem erhöhten Patientenrisiko bei intensivpflichtigen Patienten und der erforderlichen Schlussdesinfektion des MRT-Geräts, in der RisikoNutzen-Abwägung nur im Einzelfall indiziert. Bei dringendem Bedarf einer bildgebenden Untersuchung kann eine Muskelsonographie erfolgen $[125,135,136]$. 


\section{Therapie}

Die Therapieempfehlungen für inflammatorische/autoimmunassoziierte Erkrankungen der Muskulatur, der neuromuskulären Endplatte und des peripheren Nervens entsprechen denen der aktuellen Leitlinien inklusive aller üblichen rasch wirksamen therapeutischen Maßnahmen einschließlich Plasmaphereseverfahren und der Gabe von Immunglobulinen. Eine symptomatische (z.B. Pyridostigmin und 3,4-Diaminopyridin/Fampridin) Behandlung und die immunmodulierende Therapie einschließlich der Gabe von Steroiden bis hin $\mathrm{zu}$ Eculizumab können unter Abwägung des Nutzen-Risiko-Profils fortgeführt werden. Die Gabe von Rituximab oder die Einleitung einer oralen Langzeitimmunsuppression sollte in Abhängigkeit vom klinischen Zustand des Patienten und der Anamnese ggf. verschoben werden $[125,137,138]$.

Für alle Patienten gelten die gleichen Risikoabwägungen und Impfempfehlungen (Influenza- und Pneumokokkenimpfung) wie für Gesunde der gleichen Altersgruppe bei nur geringen Impfrisiken.

\section{Allgemeine Empfehlungen bei respiratorischer Verschlechterung}

Beim Auftreten von COVID-19-verdächtigen Symptomen nach Kontakt mit einer potenziell infizierten Person, bei respiratorischer Dekompensation beatmeter Patienten oder allgemein bei neu aufgetretenen respiratorischen Symptomen wird eine telefonische oder telemedizinische Kontaktaufnahme mit dem behandelnden Arzt sowie ggf. dem Beatmungspflegedienst empfohlen. Die Entscheidung über die Einleitung einer ambulanten oder stationären Diagnostik und Therapie wird individuell getroffen [139].

Spezifische Maßnahmen für einen Krankentransport und das Krankenhaus sind:

- Nutzung nicht belüfteter Masken mit einem Bakterien-VirenFilter am Geräteausgang

- Filter zwischen Maske und Geräteschlauch

\section{Versorgungskoordination (Was wird wo gemacht: ambulant/stationär)}

Durch neuromuskuläre Zentren werden neuromuskuläre Patienten flächendeckend telefonisch und videogestützt oder direkt persönlich unter Wahrung des Abstandsgebots ambulant, teilstationär und stationär versorgt. Es besteht ein enger Austausch mit den Patientenselbsthilfeorganisationen wie der Deutschen Gesellschaft für Muskelkranke e. V. und der „World Muscle Society" (WMS). Spezifische Vorsorge- und Therapieempfehlungen wurden veröffentlicht [139].

Wichtig für ÄrztInnen in der Notaufnahme und Intensivstation ist bei der Entscheidung zur Aufnahme, Eskalation oder Beendigung einer Behandlung von Patienten mit neuromuskulären Erkrankungen und COVID-19 die Einbeziehung neuromuskulärer SpezialistInnen und PneumologInnen [125].

Bisher haben sich aufgrund der Einhaltung der allgemeinen Hygienevorschriften mit Selbstisolierungsmaßahmen nur sehr wenige neuromuskuläre Patienten in Deutschland mit SARSCoV-2 infiziert und sind an COVID-19 erkrankt. Somit scheint kein massiv erhöhtes Risiko für neuromuskuläre Patienten unter einer SARS-CoV-2-Infektion zu bestehen. Einzelne wenige
Todesfälle von ALS- und Myastheniepatienten mit manifester COVID-19-Erkrankung sind im LEOSS-Register registriert.

\section{Neurologische Intensivmedizin}

Bearbeitet von Georg Gahn, Karlsruhe, und Julian Bösel, Kassel

\section{Definition}

Berichte über eine neurologische Beteiligung bei COVID-19 mehren sich, besonders bei Patienten mit schweren Verläufen, sodass diese Thematik besonders die neurologische Intensivtherapie betrifft. Hierunter fallen z. B. Enzephalitis, Enzephalopathie, Status epilepticus, ausgedehnte oder multiple ischämische und hämorrhagische Schlaganfälle und schwere (Poly-)Neuropathien wie das Guillain-Barré-Syndrom.

Das Nervensystem kann direkt und indirekt miteinbezogen werden, wobei Letzteres vermutlich zahlenmäßig überwiegt. Diese Unterscheidung kann für die diagnostische und therapeutische Versorgung wichtig sein, auch für die Prognose der COVID-19-Patienten. Die Kenntnis neurologischer Beteiligungen kann auch für die Strategie der supportiven Intensivtherapie eine Rolle spielen. So könnten manche Therapieformen wie ECMO in Unkenntnis von z. B. ausgedehnten Hirninfarkten ungünstig verlaufen. Neurologische Manifestationen von COVID-19 können leicht in der schwerwiegenden, pulmonal dominierten Intensivsituation maskiert bleiben. Deshalb muss aktiv nach einer Mitbeteiligung des zentralen oder peripheren Nervensystems gesucht werden.

Bezüglich weitreichender, allgemeiner Prinzipien der Intensivmedizin bei COVID-19 schließen sich die DGN wie auch die DGNI der S1-Leitlinie „Empfehlungen zur intensivmedizinischen Therapie von Patienten mit COVID-19" unter Federführung von DGIIN und DIVI [140] an. Bezüglich der speziellen neurointensivmedizinischen Aspekte werden im Folgenden Ergänzungen zu einigen Abschnitten dieser S1-Leitlinie gemacht:

\section{Diagnostik}

Intensivmedizinisch bedeutsame neurologische Krankheitsbilder sind die Meningoenzephalitis, schwere ischämische oder hämorrhagische Schlaganfälle, rasch fortschreitende Polyneuropathien, -neuritiden oder eine ,intensive care unit-acquired weakness".

Zusätzlich zur üblichen Erregerdiagnostik auf SARS-CoV-2 sollte auch eine Basisdiagnostik inklusive RT-PCR-Test aus dem Liquor erfolgen, sofern der klinische Verdacht auf eine (Meningo-)Enzephalitis, ein Delir oder eine Polyneuritis besteht und gegen die Lumbalpunktion keine Kontraindikationen vorliegen.

Bei unklarer verzögerter Aufwachreaktion, unklarem Delir sowie Hinweisen auf einen konvulsiven oder nichtkonvulsiven Status epilepticus sollte ein EEG abgeleitet werden [141].

\section{Bildgebung}

Bei fokalen neurologischen Ausfallssymptomen, wie z. B. einer halbseitigen Lähmung, Störungen der Okulomotorik oder Pyramidenbahnzeichen sollten eine zerebrale und ggf. auch eine spinale Bildgebung, möglichst als MRT, sowie eine Diagnostik der hirnversorgenden Gefäße erfolgen. Bei manchen Patienten, die aufgrund schweren intensivmedizinischen Verlaufs und/ oder Analgosedierung nicht zuverlässig klinisch untersuchbar 
sind, kann dies auch prophylaktisch angezeigt sein (z.B. zerebrales CT vor ECMO bei der Möglichkeit hämorrhagischer oder ischämischer Infarkte, [142, 143]).

\section{Hirnödem und erhöhter intrakranieller Druck}

Die Optimierung der Beatmungsparameter kann den intrakraniellen Druck beeinflussen. Eine invasive Beatmung mit PEEP („positive end-expiratory pressure“), einer permissiven Hyperkapnie oder in Bauchlagerung kann zu einer Erhöhung des intrakraniellen Drucks führen. Hierzu ist die Datenlage allerdings uneinheitlich. Daher erfordert das Vorgehen stets eine individuelle Nutzen-Risiko-Abwägung [144-146].

Ein multimodales Neuromonitoring (z.B. ICP-/CPP-Messung, NIRS, transkranieller Doppler/Duplex, sonographische Messung des Sehnervenscheidendurchmessers) kann das therapeutische Vorgehen bei Patienten mit erhöhtem intrakraniellem Druck erleichtern [147, 148].

Literatur

Verwendete Literatur

1. Chaumont H, Etienne P, Roze E, Couratier C, Roger PM, Lannuzel A (2020) Acute meningoencephalitis in a patient with COVID-19. Rev Neurol 176(6):519-521

2. Ghannam M, Alshaer Q, Al-Chalabi M, Zakarna L, Robertson J, Manousakis G (2020) Neurological involvement of coronavirus disease 2019: a systematic review. J Neurol. https://doi.org/10.1007/s00415-020-09990-2

3. Pilotto A, Odolini S, Masciocchi S, Comelli A, Volonghi l, Gazzina S et al (2020) Steroid-responsive encephalitis in Coronavirus disease 2019. Ann Neurol. https:// doi.org/10.1002/ana.25783

4. Duong L, XU P, Liu A (2020) Meningoencephalitis without respiratory failure in a young female patient with COVID-19 infection in Downtown Los Angeles, early April 2020. Brain Behav Immun 87:33

5. Dogan L, Kaya D, Sarikaya T, Zengin R, Dincer A, Akinci IO et al (2020) Plasmapheresis treatment in COVID-19-related autoimmune meningoencephalitis: Case series. Brain Behav Immun 87:155-158

6. Li YC, Bai WZ, Hashikawa T (2020) The neuroinvasive potential of SARS-CoV2 may play a role in the respiratory failure of COVID-19 patients. J Med Virol 92(6):552-555

7. Alberti P, Beretta S, Piatti M, Karantzoulis A, Piatti ML, Santoro P, Viganò M, Giovannelli G, Pirro F, Montisano DA, Appollonio I, Ferrarese C (2020) GuillainBarré syndrome related to COVID-19 infection. Neurol Neuroimmunol Neuroinflamm 7(4):e741. https://doi.org/10.1212/NXI.0000000000000741

8. Arnaud S, Budowski C, Ng Wing Tin S, Degos B (2020) Post SARS-CoV-2 GuillainBarre syndrome. Clin Neurophysiol 131(7):1652-1654

9. Camdessanche JP, Morel J, Pozzetto B, Paul S, Tholance Y, Botelho-Nevers E (2020) COVID-19 may induce Guillain-Barre syndrome. Rev Neurol 176(6):516-518

10. El Otmani H, El Moutawakil B, Rafai MA, El Benna N, El Kettani C, Soussi M et al (2020) Covid-19 and Guillain-Barre syndrome: more than a coincidence! Rev Neurol 176(6):518-519

11. Gutierrez-Ortiz C, Mendez A, Rodrigo-ReyS, San Pedro-Murillo E, BermejoGuerrero L, Gordo-Manas Ret al (2020) Miller Fisher Syndrome and polyneuritis cranialis in COVID-19. Neurology 95(5):e601-e605

12. Novi G, Rossi T, Pedemonte E, Saitta L, Rolla C, Roccatagliata L, Inglese M, Farinini D (2020) Acute disseminated encephalomyelitis after SARS-CoV-2 infection. Neurol Neuroimmunol Neuroinflamm 7(5):e797. https://doi.org/10. 1212/NXI.0000000000000797

13. Padroni M, Mastrangelo V, Asioli GM, Pavolucci L, Abu-Rumeileh S, Piscaglia MG et al (2020) Guillain-Barre syndrome following COVID-19: new infection, old complication? J Neurol 267(7):1877-1879
14. Pfefferkorn T, Dabitz R, von Wernitz-Keibel T, Aufenanger J, Nowak-Machen M, Janssen $H$ (2020) Acute polyradiculoneuritis with locked-in syndrome in a patient with Covid-19. J Neurol 267(7):1883-1884

15. Scheidl E, Canseco DD, Hadji-Naumov A, Bereznai B (2020) Guillain-Barre syndrome during SARS-COV-2 pandemic: a case report and review of recent literature. J Peripher Nerv Syst 25(2):204-207

16. Sedaghat Z, Karimi N (2020) Guillain Barre syndrome associated with COVID-19 infection: a case report. J Clin Neurosci 76:233-235

17. SuXW, Palka SV, Rao RR, Chen FS, Brackney CR, Cambi F (2020) SARS-CoV-2associated Guillain-Barre syndrome with dysautonomia. Muscle Nerve 62(2):E48-E49

18. Toscano G, Palmerini F, Ravaglia S, Ruiz L, Invernizzi P, Cuzzoni MG et al (2020) Guillain-Barre Syndrome Associated with SARS-CoV-2. N Engl J Med 382(26):2574-2576

19. Zhao H, Shen D, Zhou H, Liu J, Chen S (2020) Guillain-Barre syndrome associated with SARS-COV-2 infection: causality or coincidence? Lancet Neurol 19(5):383-384

20. Pfeuffer S, Pawlowski M, Joos G, Minnerup J, Meuth SG, Dziewas R, Wiendl H (2020) Autoimmunity complicating SARS-CoV-2 infection in selective IgAdeficiency. Neurol Neuroimmunol Neuroinflamm 7(6):e881. https://doi.org/10. 1212/NXI.0000000000000881

21. Parsons T, Banks S, Bae C, Gelber J, Alahmadi H, Tichauer M (2020) COVID-19associated acute disseminated encephalomyelitis (ADEM). J Neurol 267(10):2799-2802. https://doi.org/10.1007/s00415-020-09951-9

22. Reichard RR, Kashani KB, Boire NA, Constantopoulos E, Guo Y, Lucchinetti CF (2020) Neuropathology of COVID-19: a spectrum of vascular and acute disseminated encephalomyelitis (ADEM)-like pathology. Acta Neuropathol 140(1):1-6

23. Poyiadji N, Shahin G, Noujaim D, Stone M, Patel S, Griffith B (2020) COVID-19associated acute hemorrhagic necrotizing encephalopathy: CT and MRI features. Radiology. https://doi.org/10.1148/radiol.2020201187

24. Barzegar M, Mirmosayyeb O, Nehzat N, Sarrafi R, Khorvash F, Maghzi AH, Shaygannejad V (2020) COVID-19 infection in a patient with multiple sclerosis treated with fingolimod. Neurol Neuroimmunol Neuroinflamm 7(4):e753. https:// doi.org/10.1212/NXI.0000000000000753

25. Borriello G, lanniello A (2020) COVID-19 occurring during Natalizumab treatment: a case report in a patient with extended interval dosing approach. Mult Scler Relat Disord 41:102165

26. Foerch C, Friedauer L, Bauer B, Wolf T, Adam EH (2020) Severe COVID-19 infection in a patient with multiple sclerosis treated with fingolimod. Mult Scler Relat Disord 42:102180

27. Ghajarzadeh M, Mirmosayyeb O, Barzegar M, Nehzat N, VahebS, Shaygannejad V et al (2020) Favorable outcome after COVID-19 infection in a multiple sclerosis patient initiated on ocrelizumab during the pandemic. Mult Scler Relat Disord 43:102222

28. Maghzi AH, Houtchens MK, Preziosa P, lonete C, Beretich BD, Stankiewicz JM, Tauhid S, Cabot A, Berriosmorales I, Schwartz T, Sloane JA, Freedman MS, Filippi M, Weiner HL, Bakshi R (2020) COVID-19 in teriflunomide-treated patients with multiple sclerosis. J Neurol 267(10):2790-2796. https://doi.org/10.1007/ s00415-020-09944-8

29. Suwanwongse K, Shabarek N (2020) Benign course of COVID-19 in a multiple sclerosis patient treated with Ocrelizumab. Mult Scler Relat Disord 42:102201

30. Sormani MP, Italian Study Group on C-iims (2020) An Italian programme for COVID-19 infection in multiple sclerosis. Lancet Neurol 19(6):481-482

31. Ciampi E, Uribe-San-Martin R, Carcamo C (2020) COVID-19 pandemic: the experience of a multiple sclerosis centre in Chile. Mult Scler Relat Disord 42:102204

32. Fan M, Qiu W, Bu B, Xu Y, Yang H, Huang D, Lau AY, Guo J, Zhang MN, Zhang X, Yang CS, Chen J, Zheng P, Liu Q, Zhang C, Shi FD (2020) Risk of COVID-19 infection in MS and neuromyelitis optica spectrum disorders. Neurol Neuroimmunol Neuroinflamm 7(5):e787. https://doi.org/10.1212/NXI.0000000000000787

33. Pawlitzki M, ZettI UK, Ruck T, Rolfes L, Hartung HP, Meuth SG (2020) Merits and culprits of immunotherapies for neurological diseases in times of COVID-19. EBioMedicine 56:102822 
34. Zubair AS, MCAlpine LS, Gardin T, Farhadian S, Kuruvilla DE, Spudich S (2020) Neuropathogenesis and neurologic manifestations of the Coronaviruses in the age of Coronavirus disease 2019: a review. JAMA Neurol. https://doi.org/10.1001/ jamaneurol.2020.2065

35. Zheng Y, Xu H, Yang M et al (2020) Epidemiological characteristics and clinical features of 32 critical and 67 noncritical cases of COVID-19 in Chengdu. J Clin Virol 127:104366

36. Zhou P, Yang XL, Wang XG et al (2020) A pneumonia outbreak associated with a new coronavirus of probable bat origin. Nature 579(7798):270-273

37. Zhou F, Yu T, Du R et al (2020) Clinical course and risk factors for mortality of adult inpatients with COVID-19 in Wuhan, China: a retrospective cohort study. Lancet 395(10229):1054-1062

38. Chen T, Wu D, Chen H et al (2020) Clinical characteristics of 113 deceased patients with coronavirus disease 2019: retrospective study. BMJ 368:m1091

39. Mao L, Jin H, Wang M, Hu Y, Chen S, He Q, Chang J, Hong C, Zhou Y, Wang D, Miao X, Li Y, Hu B (2020) Neurologic manifestations of hospitalized patients with Coronavirus disease 2019 in Wuhan, China. JAMA Neurol 77(6):1-9. https://doi. org/10.1001/jamaneurol.2020.1127

40. Helms J, Kremer S, Merdji H, Clere-JehIR, Schenck M, Kummerlen C, Collange O, Boulay C, Fafi-Kremer S, Ohana M, Anheim M, Meziani F (2020). Neurologic Features in Severe SARS-CoV-2 Infection. New Engl J Med 382(23):2268-2270. https://doi.org/10.1056/NEJMc2008597

41. Helmsworth JA, Stiles WJ, Elstun W (1955) Leukopenic and thrombocytopenic effect of hypothermia in dogs. Proc Soc Exp Biol Med 90(2):474-476

42. Radmanesh A, Derman A, Lui YW, Raz E, Loh JP, Hagiwara M, Borja MJ, Zan E, Fatterpekar GM (2020) COVID-19-associated Diffuse Leukoencephalopathy and Microhemorrhages. Radiology 297(1):E223-E227. https://doi.org/10.1148/radiol. 2020202040

43. Filatov A, Sharma P, Hindi F, Espinosa PS (2020) Neurological complications of Coronavirus disease (COVID-19): encephalopathy. Cureus 12(3):e7352

44. Neumann B, Schmidbauer ML, Dimitriadis K, Otto S, Knier B, Niesen WD, Hosp JA, Günther A, Lindemann S, Nagy G, Steinberg T, Linker RA, Hemmer B, Bösel J, Pandemic and the IGNITE study groups (2020) Cerebrospinal fluid findings in COVID-19 patients with neurological symptoms. J Neurolog Sc 418:117090. https://doi.org/10.1016/j.jns.2020.117090

45. Desforges M, Le Coupanec A, Brison E, Meessen-Pinard M, Talbot PJ (2014) Neuroinvasive and neurotropic human respiratory coronaviruses: potential neurovirulent agents in humans. Adv Exp Med Biol 807:75-96. https://doi.org/10. 1007/978-81-322-1777-0 6

46. Baig AM, Khaleeq A, Ali U, Syeda H (2020) Evidence of the COVID-19 virus targeting the CNS: tissue distribution, host-virus interaction, and proposed neurotropic mechanisms. ACS Chem Neurosci 11(7):995-998

47. Sepehrinezhad A, Shahbazi A, Negah SS (2020) COVID-19 virus may have neuroinvasive potential and cause neurological complications: a perspective review. J Neurovirol 26(3):324-329. https://doi.org/10.1007/s13365-020-008512

48. Yan CH, Faraji F, Prajapati DP, Boone CE, DeConde AS (2020) Association of chemosensory dysfunction and COVID-19 in patients presenting with influenzalike symptoms. Internat Forum Allergy Rhinol 10(7):806-813. https://doi.org/10. 1002/alr.22579

49. Moriguchi T, Harii N, Goto J et al (2020) A first case of meningitis/encephalitis associated with SARS-Coronavirus-2. Int I Infect Dis 94:55-58

50. Huang YH, Jiang D, Huang JT (2020) SARS-CoV-2 Detected in Cerebrospinal Fluid by PCR in a Case of COVID-19 Encephalitis. Brain Behav Immun 87:149. https:// doi.org/10.1016/j.bbi.2020.05.012

51. Paniz-Mondolfi A, Bryce C, Grimes Z, Gordon RE, Reidy J, Lednicky J, Sordillo EM, Fowkes M (2020) Central nervous system involvement by severe acute respiratory syndrome coronavirus-2 (SARS-CoV-2). J Med Virol 92(7):699-702. https://doi. org/10.1002/jmv.25915

52. Puelles VG, Lütgehetmann $M$, Lindenmeyer MT, Sperhake JP, Wong MN, Allweiss L, Chilla S, Heinemann A, Wanner N, Liu S, Braun F, Lu S, PfefferleS, Schröder AS, Edler C, Gross O, Glatzel M, Wichmann D, Wiech T, Kluge S, Huber TB (2020)
Multiorgan and Renal Tropism of SARS-CoV-2. New England J Med 383(6):590-592.https://doi.org/10.1056/NEJMc2011400

53. Politi LS, Salsano E, Grimaldi M (2020) Magnetic resonance imaging alteration of the brain in a patient with coronavirus disease 2019 (COVID-19) and anosmia. Jama Neurol. https://doi.org/10.1001/jamaneurol.2020.2125

54. Bernard-Valnet R, Pizzarotti B, Anichini A, Demars Y, Russo E, Schmidhauser M, Cerutti-Sola J, Rossetti AO, Du Pasquier R (2020) Two patients with acute meningoencephalitis concomitant with SARS-CoV-2 infection. Europ J Neurol. https://doi.org/10.1111/ene.14298

55. Pilotto A, Odolini S, Masciocchi S, Comelli A, Volonghi I, Gazzina S, Nocivelli S, Pezzini A, Focà E, Caruso A, Leonardi M, Pasolini MP, Gasparotti R, Castelli F, Ashton NJ, Blennow K, Zetterberg H, Padovani A (2020) Steroid-Responsive Encephalitis in Coronavirus Disease 2019. Annals Neurol. https://doi.org/10. 1002/ana.25783

56. Dogan L, Kaya D, Sarikaya T, Zengin R, Dincer A, Akinci IO, Afsar N (2020) Plasmapheresis treatment in COVID-19-related autoimmune meningoencephalitis: Case series. Brain Behavior Immunity 87:155-158. https:// doi.org/10.1016/j.bbi.2020.05.022

57. Klok FA, Kruip MJHA, van der Meer NJM et al (2020) Incidence of thrombotic complications in critically ill ICU patients with COVID-19. Thromb Res. https://doi. org/10.1016/j.thromres.2020.04.013

58. Li Y, Li M, Wang M, Zhou Y, Chang J, Xian Y, Wang D, Mao L, Jin H, Hu B (2020) Acute cerebrovascular disease following COVID-19: a single center, retrospective, observational study. Stroke Vascul Neurol 5(3):279-284. https://doi.org/10.1136/ svn-2020-000431

59. Zhang Y, Xiao M, Zhang Set al (2020) Coagulopathy and Antiphospholipid antibodies in patients with COVID-19. N Engl J Med 382:e38

60. Merkler AE, Parikh NS, Mir S, Gupta A, Kamel H, Lin E, Lantos J, Schenck EJ, Goyal P, Bruce SS, Kahan J, Lansdale KN, LeMoss NM, Murthy SB, Stieg PE, Fink ME, ladecola C, Segal AZ, Campion TR Jr, Diaz I, Navi BB (2020) Risk of Ischemic Stroke in Patients with Covid-19versus Patients with Influenza. medRxiv: the preprint server for health sciences. https://doi.org/10.1101/2020.05.18.20105494

61. Yamakawa M, Kuno T, Mikami T, Takagi H, Gronseth G (2020) Clinical Characteristics of Stroke with COVID-19: A Systematic Review and Meta-Analysis. J Stroke Cerebrovascular diseases 29(12):105288. https://doi.org/10.1016/j. jstrokecerebrovasdis.2020.105288

62. Yhagi S, Ishida K, Torres J et al (2020) SARS2-coV-2 and stroke in a New York healthcare system. Stroke. https://doi.org/10.1161/STROKEAHA.120.030335

63. Oxley TJ, Mocco J, Majidi S et al (2020) Clinical characteristics of five young patients presenting with large-vessel stroke. N Eng J Med. https://doi.org/10. 1056/NEJMc2009787

64. Aggarwal G, Lippi G, Henry MB (2020) Cerebrovascular disease is associated with an increased disease severity in patients with coronavirus disease 2019 (COVID-

19): a pooled analysis of published literature. Int J Stroke. https://doi.org/10. 1177/174749302092166418

65. Pop R, Quenardelle V, Hasiu A, Mihoc D, Sellal F, Dugay MH (2020) Impact of the COVID-19 outbreak on acute stroke pathways -insights from the Alsace region in France. Eur J Neurol. https://doi.org/10.1111/ene. 14316

66. Baracchini C, Pieroni A, Viaro F et al (2020) Acute stroke management pathway during Coronavirus-19 pandemic. Neurol Sci 41:1003-1005. https://doi.org/10. 1007/s10072-020-04375-9

67. Zhao J, Li H, Kung D, Fisher M, Shen Y, Liu R (2020) Impact of the COVID-19 epidemic on stroke care and potential solutions. Stroke. https://doi.org/10.1161/ STROKEAHA. 120.030225

68. Leira EC, Russmann AN, Biller J et al (2020) Preserving stroke care during the COVID-19 pandemic. Potential issues and solutions. Neurology. https://doi.org/ 10.1212/WNL.0000000000009713

69. Yang B, Wang T, Chen J et al (2020) Impact of the COVID-19 pandemic on the process and outcome of thrombectomy for acute ischemic stroke. J Neurointerv Surg 12(7):664-668

70. Khosravani H, Rajendram P, Notario L, Chapman MG, Menon BK (2020) Protected Code Stroke: Hyperacute Stroke Management During the Coronavirus Disease 
2019 (COVID-19) Pandemic. Stroke 51(6):1891-1895.https://doi.org/10.1161/ STROKEAHA. 120.029838

71. Sharma D, Rasmussen M, Han Ret al (2020) Anesthetic Management of Endovascular Treatment of Acute Ischemic Stroke During COVID-19 Pandemic: Consensus Statement From Society for Neuroscience in Anesthesiology \& Critical Care (SNACC): Endorsed by Society of Vascular \& Interventional Neurology (SVIN), Society of Neurolnterventional Surgery (SNIS), Neurocritical Care Society (NCS), European Society of Minimally Invasive Neurological Therapy (ESMINT) and American Association of Neurological Surgeons (AANS) and Congress of Neurological Surgeons (CNS) Cerebrovascular Section. J Neurosurg Anesthesiol 32(3):193-201

72. Qureshi Al, Abd-Allah F, Al-Senani F, Aytac E, Borhani-Haghighi A, Ciccone A, Gomez CR, Gurkas E, Hsu CY, Jani V, Jiao L, Kobayashi A, Lee J, Liaqat J, Mazighi M, Parthasarathy R, Miran MS, Steiner T, Toyoda K, Ribo M, Wang Y (2020) Management of acute ischemic stroke in patients with COVID-19 infection: Insights from an international panel. Amer J Emerg Med 38(7):1548.e5-1548.e7. https://doi.org/10.1016/j.ajem.2020.05.018

73. Beghi E, Carpio A, Forsgren L, Hesdorffer DC, Malmgren K, Sander JW, Tomson T, Hauser WA (2010) Recommendation for a definition of acute symptomatic seizure. Epilepsia 51(4):671-675

74. DGN-Kommission Epilepsien und Synkopen. Stellungnahme der Kommission zu Covid-19 Infektionen und Epilepsie. www.dgn.org/rubrik-dgn/3771-2-19epilepsien-und-synkopen

75. French JA, Brodie MA, Caraballo R, Devinsky O, Ding D, Jehi L, Jette N, Kanner A, Modi AC, Newton CR, Patel AA, Pennell PB, Perucca E, Sander JW, Scheffer IE, Williams E, Wilmshorst J, Cross JH (2020) Keeping people with epilepsy safe during the Covid pandemic. Neurology 94(23):1032-1037. https://doi.org/10.1212/ WNL.0000000000009632

76. Karimi N, Shafiri Razavi A, Rouhani N (2020) Frequent convulsive seizures in an adult patient with COVID-19: a case report. Iran Red Crescent Med J 22(3):e102828

77. Lu L, Xiong W, Liu D, Liu J, Yang D, Li N, Mu J, Guo J, Li W, Wang G, Gao H, Zhang Y, Lin M, Chen L, Shen S, Zhang H, Sander JW, Luo J, Chen S, Zhou D (2020) New onset acute symptomatic seizure and risk factors in coronavirus disease 2019: A retrospective multicenter study. Epilepsia 61(6):e49-e53. https://doi.org/10. 1111/epi.16524

78. Wu Y, XuX, Chen Z, Duan J, Hashimoto K, Yang L et al (2020) Nervous system involvement after infection with COVID-19 and other coronaviruses. Brain Behav Immun. https://doi.org/10.1016/j.bbi.2020.03.031

79. Vollono C, Rollo E, Romozzi M, Frisullo G, Servidei S, Borghetti A, Calabresi P (2020) Focal status epilepticus as unique clinical feature of COVID-19: a case report. Seizure 78:109-112.https://doi.org/10.1016/i.seizure.2020.04.009

80. Lai SL, Hsu MT, Chen SS (2005) The impact of SARS on epilepsy: the experience of drug withdrawal in epileptic patients. Seizure 14(8):557-561

81. Moriguchi T, Harii N, Goto J, Harada D, Sugawara H, Takamino J, Ueno M, Sakata H, Kondo K, Myose N, Nakao A, Takeda M, Haro H, Inoue O, Suzuki-Inoue K, Kubokawa K, Ogihara S, Sasaki T, Kinouchi H, Kojin H, Ito M, Onishi H, Shimizu T, Sasaki Y, Enomoto N, Ishihara H, Furuya S, Yamamoto T, Shimada S (2020) A first case of meningitis/encephalitis associated with SARS-Coronavirus-2. Int I Infect Dis 94:55-58

82. Hummel T, Whitcroft KL, Andrews P, Altundag A, Cinghi C, Costanzo RM, Damm M, Frasnelli J, Gudziol H, Gupta N, Haehner A, Holbrook E, Hong SC, Hornung D, Hüttenbrink KB, Kamel R, Kobayashi M, Konstantinidis I, Landis BN, Leopold DA, Macchi A, Miwa T, Moesges R, Mullol J, Mueller CA, Ottaviano G, Passali GC, Philpott C, Pinto JM, Ramakrishnan VJ, Rombaux P, Roth Y, Schlosser RA, Shu B, Soler G, Stjärne P, Stuck BA, Vodicka J, Welge-Luessen A (2017) Position paper on olfactory dysfunction. Rhinol Suppl 25:1-30

83. Stevenson RJ (2010) An initial evaluation of the functions of human olfaction. Chem Senses 35(1):3-20. https://doi.org/10.1093/chemse/bjp083

84. Buck L, Axel R (1991) A novel multigene family may encode odorant receptors: a molecular basis for odor recognition. Cell 65(1):175-187. https://doi.org/10. 1016/0092-8674(91)90418-x
85. Shepherd GM (2007) Perspectives on olfactory processing, conscious perception, and orbitofrontal cortex. Ann N Y Acad Sci 1121:87-101. https://doi.org/10. 1196/annals. 1401.032

86. DeMaria S, Ngai J (2010) The cell biology of smell. J Cell Biol 191(3):443-452. https://doi.org/10.1083/jcb.201008163

87. Bednár M (1930) Anosmie und Influenza (Ein rhinologischer Beitrag zur Differentialdiagnose der Erkältungskrankheiten). Med Klin 48:1787-1789

88. Konstantinidis I, Haehner A, Frasnelli J, Reden J, Quante G, Damm M, Hummel T (2006) Post-infectious olfactory dysfunction exhibits a seasonal pattern. Rhinology 44:135-139

89. Schaupp H (1972) Geruchsstörungen nach Grippe. Arch Klin Exp Ohren Nasen Kehlkopfheilkd 199:692-698

90. Sugiura M, Aiba T, Mori J, Nakai Y (1998) An epidemiological study of postviral olfactory disorder. Acta Otolaryngol Suppl 538:191-196

91. Arbour N, Day R, Newcombe J, Talbot PJ (2000) Neuroinvasion by human respiratory coronaviruses. J Virol 74(19):8913-8921. https://doi.org/10.1128/jvi. 74.19.8913-8921.2000

92. Wu Y, Xu X, Chen Z et al (2020) Nervous system involvement after infection with COVID-19 and other coronaviruses. Brain Behav Immun 87:18-22. https://doi. org/10.1016/j.bbi.2020.03.031

93. Li W, Moore MJ, Vasilieva N, Sui J, Wong SK, Berne MA, Somasundaran M, Sullivan JL, Luzuriaga K, Greenough TC, Choe H, Farzan M (2003) Angiotensinconverting enzyme 2 is a functional receptor for the SARS coronavirus. Nature 426:450-454

94. Netland J, Meyerholz DK, Moore S, Cassell M, Perlman S (2008) Severe acute respiratory syndrome coronavirus infection causes neuronal death in the absence of encephalitis in mice transgenic for human ACE2. J Virol 82(15):7264-7275. https://doi.org/10.1128/JVI.00737-08

95. Hwang CS (2006) Olfactory neuropathy in severe acute respiratory syndrome: report of a case. Acta Neurol Taiwan 15(1):26-28

96. Sungnak W, Huang N, Bécavin C, Berg M, Queen R, Litvinukova M, TalaveraLópez C, Maatz H, Reichart D, Sampaziotis Fet al (2020) 2020. SARS-cov-2 entry factors are highly expressed in nasal epithelial cells together with innate immune genes. Nat Med 26(5):681-687. https://doi.org/10.1038/s41591-020-0868-6

97. Hoffmann M, Kleine-Weber H, Schroeder S et al (2020) SARS-coV-2 cell entry depends on ACE2 and TMPRSS2 and is blocked by a clinically proven protease inhibitor. Cell 181(2):271-280.e8.https://doi.org/10.1016/icell.2020.02.052

98. Kirschenbaum D, Imbach LL, Ulrich S, Rushing EJ, Keller E, Reimann RR, Frauenknecht K, Lichtblau M, Witt M, Hummel T, Steiger P, Aguzzi A, Frontzek K (2020) Inflammatory olfactory neuropathy in two patients with COVID-19. Lancet 396(10245):166. https://doi.org/10.1016/S0140-6736(20)31525-7

99. van Riel D, Verdijk R, Kuiken T (2015) The olfactory nerve: a shortcut for influenza and other viral diseases into the central nervous system. J Pathol 235:277-287. https://doi.org/10.1002/path.4461

100. Puelles VG, Lütgehetmann M, Lindenmeyer MT et al (2020) Multiorgan and renal tropism of SARS-coV-2. N Eng J Med. https://doi.org/10.1056/NEJMc2011400

101. Zhu N, Zhang D, Wang W et al (2020) A Novel Coronavirus from Patients with Pneumonia in China, 2019. N Engl J Med 382:727-733

102. Guan WJ, Ni ZY, Hu Y et al (2020) Clinical characteristics of Coronavirus disease 2019 in China. N Engl J Med. https://doi.org/10.1056/NEJMoa2002032

103. Huang C, Wang Y, Li X et al (2020) Clinical features of patients infected with 2019 novel coronavirus in Wuhan, China. Lancet 395:497-506

104. Grasselli G, Zangrillo A, Zanella A et al (2020) Baseline characteristics and outcomes of 1591 patients infected with SARS-coV-2 admitted to ICus of the Lombardy region, Italy. JAMA. https://doi.org/10.1001/jama.2020.5394

105. Dreher MKA, Kersten A, Bickenbach J et al (2020) Charakteristik von 50 hospitalisierten COVID-19-Patienten mit und ohne ARDS. Dtsch Arztebl Int 117:271-278. https://doi.org/10.3238/arztebl.2020.0271

106. Bagheri SH, Asghari A, Farhadi M, Shamshiri AR, Kabir A, Kamrava SK, Jalessi M, Mohebbi A, Alizadeh R, Honarmand AA, Ghalehbaghi B, Salimi A, Dehghani Firouzabadi $F$ (2020) Coincidence of COVID-19 epidemic and olfactory dysfunction outbreak in Iran. Med J Islamic Rep Iran 34:62. https://doi.org/10. 34171/mjiri.34.62 
107. https://dgn.org/wp-content/uploads/2020/08/030144_Tabellen_Stoerungen_ der_Chemosensorik-1.pdf

108. Hintschich CA, Wenzel JJ, Hummel T et al (2020) Psychophysical tests reveal impaired olfaction but preserved gustation in COVID-19 patients. Int Forum Allergy Rhinol. https://doi.org/10.1002/alr.22655

109. Haehner A, Draf J, Dräger S, de With K, Hummel T (2020) Predictive value of sudden olfactory loss in the diagnosis of COVID-19. Orl J Otorhinolaryngol Relat Spec. https://doi.org/10.1159/000509143

110. Whitcroft KL, Hummel T (2019) Clinical diagnosis and current management strategies for olfactory dysfunction: a review. JAMA Otolaryngol Head Neck Surg. https://doi.org/10.1001/jamaoto.2019.1728

111. Zou LQ, Linden L, Cuevas M, Metasch ML, Welge-Lüssen A, Hähner A, Hummel T (2019) Self-reported mini olfactory questionnaire (Self-MOQ): a simple and useful measurement for the screening of olfactory dysfunction. Laryngoscope. https:// doi.org/10.1002/lary.28419

112. Doty RL, Shaman P, Dann M (1984) Development of the university of Pennsylvania smell identification test: a standardized microencapsulated test of olfactory function. Physiol Behav 32:489-502

113. Dietz A, Haxel B, Müller A, Welkoborsky HJ, Drumm S, Guntinas-Lichius O, Chaberny I, Wienke A, Deitmer T, Heinrich D (2020) Handlungsempfehlungen DGHNO-KHC und BVHNO für die HNO-Elektiv-/nicht notfallmäßige Behandlung zu Corona-Zeiten (29.04.2020). Laryngorhinootologie 99(06):365-369

114. Vaira LA, Salzano G, Petrocelli M, Deiana G, Salzano FA, De Riu G (2020) Validation of a self-administered olfactory and gustatory test for the remotely evaluation of COVID-19 patients in home quarantine. Head Neck. https://doi.org/10.1002/hed. 26228

115. Petrocelli M, Ruggiero F, Baietti AM et al (2020) Remote psychophysical evaluation of olfactory and gustatory functions in early-stage coronavirus disease 2019 patients: the Bologna experience of 300 cases. J Laryngol Otol. https://doi. org/10.1017/S0022215120001358

116. Lee DY, Lee WH, Wee JH, Kim JW (2014) Prognosis of postviral olfactory loss: follow-up study for longer than one year. Am J Rhinol Allergy 28(5):419-422. https://doi.org/10.2500/ajra.2014.28.4102

117. Reden J, Mueller A, Mueller C, Konstantinidis I, Frasnelli J, Landis BN, Hummel T (2006) Recovery of olfactory function following closed head injury or infections of the upper respiratory tract. Arch Otolaryngol Head Neck Surg 132:265-269

118. Hüttenbrink KB et al Riech-und Schmeckstörungen. S2k-Leitlinie der DGHNOKHC. Stand: 31.10.2016. AWMF online. https://www.awmforg/leitlinien/detail/II/ 017-050.html. Zugegriffen: 30. Juni 2020

119. Wang D, Hu B, Hu C, Zhu F, Liu X, Zhang J, Wang B, Xiang H, Cheng Z, Xiong Y, Zhao Y, Li Y, Wang X, Peng Z (2020) Clinical characteristics of 138 hospitalized patients with 2019 novel Coronavirus infected pneumonia in Wuhan, China. JAMA 323(11):1061-1069

120. Guan W, Zyi N, Hu Y, Liang W, Ou C, He J, Liu L, Shan H, Lei C, Hui DSC, Du B, Li L, Zeng G, Yuen K-Y, Chen R, Tang C, Wang T, Chen P, Xiang J, Li S, Wang L, Liang Z, Peng Y, Wei L, Liu Y, Hu Y, Peng P, Wang J, Liu J, Chen Z, Li G, Zheng Z, Qiu S, Luo L, Ye C, Zhu S, Zhong N (2020) Clinical characteristics of Coronavirus disease 2019 in China. NEngl J Med 382:1708-1720

121. Huang C, Wang Y, Li X, Ren L, Zhao J, Hu Y, Zhang L, Fan G, Xu J, Gu X, Cheng Z, Yu Y, Xia J, Wei Y, Wu W, Xie X, Yin W, Li H, Liu M, Xiao Y, Gao H, Guo L, Xie J, Wang G, Jiang R, Gao Z, Jin Q, Wang J, Cao B (2020) Clinical features of patients infected with 2019 novel coronavirus in Wuhan, China. Lancet 395:497-506

122. Zhou F, Yu T, Du R, Fan G, Liu Y, Xiang J, Wang Y, Song B, Gu X, Guan L, Wie Y, Li H, Wu X, Xu J, Tu S, Zhang Y, Chen H, Cao B (2020) Clinical course and risk factors for mortality of adult inpatients with COVID-19 in Wuhan, China: a retrospective cohort study. Lancet 395:1055-1062

123. Jin M, Tong Q (2020) Rhabdomyolysis as potential late complication associated with COVID-19. Emerg Infect Dis. https://doi.org/10.3201/eid2607.200445

124. Beydon M, Chevalier K, Al Tabaa O, Hamroun S, Delettre A-S, Thomas M, Herrou J, Riviere E, Mariette X (2020) Myositis as a manifestation of SARS-CoV-2. Ann Rheum Dis. https://doi.org/10.1136/annrheumdis-2020-217573
125. Schoser et al (2020) SARS-CoV-2/COVID-19 und neuromuskuläre Erkrankungen. DGNeurologie 18:1-10. https://doi.org/10.1007/s42451-020-00198-2

126. Resivo DA, Centonze D, Alesina A, Marchese-Ragona R (2020) Myasthenia Gravis associated with SARS-coV-2 infection. Ann Intern Med. https://doi.org/10.7326/ L20-0845

127. Alberti P, Beretta S, Piatti M, Karantzoulis A, Piatti ML, Santoro P, Viganò M, Giovannelli G, Pirro F, Montisano DA, Appollonio I, Ferrarese C (2020) GuillainBarré syndrome related to COVID-19 infection. Neurol Neuroimmunol Neuroinflamm. https://doi.org/10.1212/NXI.0000000000000741

128. Toscano G, Palmerini F, Ravaglia S, Ruiz L, Invernizzi P, Cuzzoni MG, Franciotta D, Baldanti F, Daturi R, Postorino P, Cavallini A, Micieli G (2020) Guillain-Barré syndrome associated with SARS-coV-2. N Eng/ J Med. https://doi.org/10.1056/ NEJMC2009191

129. Dinkin M, Gao V, Kahan J, Bobker S, Simonetto M, Wechsler P, Harpe J, Greer C, Mints G, Salama G, Tsiouris AJ, Leifer D (2020) COVID-19 presenting with ophthalmoparesis from cranial nerve palsy. Neurology. https://doi.org/10.1212/ WNL.00000000000009700

130. Saccheri C, Morawiec E, Delemazure J, Mayaux J, Dubé B, Similowski T, Demoule A, Dres M (2020) ICU-acquired weakness, diaphragm dysfunction and long-term outcomes of critically ill patients. Ann Intensive Care 10(1):1

131. van Gassel RJJ, Baggerman MR, van de Poll MCG (2020) Metabolic aspects of muscle wasting during critical illness. Curr Opin Clin Nutr Metab Care 23(2):96-101

132. van Aerde N, Meersseman P, Debaveye Y, Wilmer A, Gunst J, Casaer MP, Bruyninckx F, Wouters PJ, Gosselink R, van den Berghe G, Hermans G (2020) Fiveyear impact of ICU-acquired neuromuscular complications: a prospective, observational study. Intensive Care Med. https://doi.org/10.1007/s00134-02005927-5

133. Pati S, Goodfellow JA, Iyadurai S, Hilton-Jones D (2008) Approach to critical illness polyneuropathy and myopathy. Postgrad Med J 84(993):354-360

134. van der Schaaf M, Beelen A, de Vos R (2004) Functional outcome in patients with critical illness polyneuropathy. Disabil Rehabil 26(20):1189-1197

135. AANEM (2020) COVID. https://www.aanem.org/Practice/COVID-19-Guidance. Zugegriffen: 10. Juni 2020

136. Special-Collection-COVID-19. https://onlinelibrary.wiley.com/doi/toc/10. 1002/(ISSN)1097-4598. Zugegriffen: 10. Juni 2020

137. International MG/COVID-19 Working Group, Jacob S, Muppidi S, Guidon A, Guptill J, Hehir M, Howard JF Jr, Illa I, Mantegazza R, Murai H, Utsugisawa K, Vissing J, Wiendl H, Nowak R (2020) Guidance for the management of myasthenia gravis (MG) and Lambert-Eaton myasthenic syndrome (LEMS) during the COVID-19 pandemic. J Neurol Sci 15:412

138. Solé G, Salort-Campana E, Pereon Y, Stojkovic T, Wahbi K, Cintas P, Adams D, Laforet P, Tiffreau V, Desquerre I, Pisella LI, Molon A, Attarian S (2020) FILNEMUS COVID-19 study group. Guidance for the care of neuromuscular patients during the COVID-19 pandemic outbreak from the French RERare Health Care for Neuromuscular Diseases Network. Rev Neurol. https://doi.org/10.1016/j.neurol. 2020.04.004

139. https://www.dgn.org/rubrik-dgn/stellungnahmen-der-dgn/3982-covid-19und-menschen-mit-neuromuskulaeren-erkrankungen-empfehlungen-derworld-muscle-society. Zugegriffen: 10.06.20.

140. Kluge S, Janssens U, Welte T, Weber-Carstens S, Marx G, Karagiannidis C (2020) Recommendations for critically ill patients with COVID-19. Med Klin Intensivmed Notfmed 115(3):175-177

141. S3-Leitlinie Analgesie, Sedierung und Delir-Management in der Intensivmedizin (DAS-Leitlinie 2015); https://www.awmf.org/uploads/tx_szleitlinien/001-0121_ S3_Analgesie_Sedierung_Delirmanagement_Intensivmedizin_2015-08_01.pdf, letzter Zugriff 30. Juni 2020

142. Sutter R, Tisljar K, Marsch S (2018) Acute Neurologic complications during extracorporeal membrane oxygenation: a systematic review. Crit Care Med 46(9):1506-1513

143. Yaghi Set al (2020) SARS2-coV-2 and stroke in a New York Healthcare system. Stroke. https://doi.org/10.1161/STROKEAHA.120.030335 
144. Rajajee V, Riggs B, Seder DB (2017) Emergency neurological life support: airway, ventilation, and sedation. Neurocrit Care 27(Suppl 1):4-28

145. Boone MD, Jinadasa SP, Mueller A, Shaefi S, Kasper EM, Hanafy KA et al (2017) The effect of positive end-expiratory pressure on Intracranial pressure and cerebral hemodynamics. Neurocrit Care 26(2):174-181

146. Chen H, Menon DK, Kavanagh BP (2019) Impact of altered airway pressure on Intracranial pressure, perfusion, and oxygenation: a narrative review. Crit Care Med 47(2):254-263

147. Le Roux P, Menon DK, Citerio G, Vespa P, Bader MK, Brophy Get al (2014) The International Multidisciplinary Consensus Conference on Multimodality Monitoring in Neurocritical Care: evidentiary tables: a statement for healthcare professionals from the Neurocritical Care Society and the European Society of Intensive Care Medicine. Neurocrit Care 21(Suppl 2):S297-S361

148. Ohle R, Mclsaac SM, Woo MY, Perry JJ (2015) Sonography of the optic nerve sheath diameter for detection of raised Intracranial pressure compared to computed tomography: a systematic review and meta-analysis. J Ultrasound Med 34(7):1285-1294

\section{Weiterführende Literatur}

149. Leslie-Mazwi TM, Fargen KM, Levitt M et al (2020) Preserving access: a review of stroke thrombectomy during the COVID-19 pandemic. AJNR Am J Neuroradiol 41:1136-1141. https://doi.org/10.3174/ajnr.A6606

150. Lodigiani C, lapichino G, Carenzo L et al (2020) Venous and arterial thromboembolic complications in COVID-19 patients admitted to an academic hospital in Milan, Italy. Thromb Res. https://doi.org/10.1016/j.thromres.2020.04. 024

151. Gutiérrez-Ortiz C, Méndez A, Rodrigo-Rey S, San Pedro-Murillo E, BermejoGuerrero L, Gordo-Mañas R, de Aragón-Gómez F, Benito-Leónet J (2020) Miller fisher syndrome and polyneuritis cranialis in COVID-19. Neurology. https://doi. org/10.1212/WNL.0000000000009619

\section{Korrespondenzadresse}

Prof. Dr. med. Peter Berlit

Deutsche Gesellschaft für Neurologie (DGN)

Reinhardstr. 27C, 10117 Berlin, Deutschland

berlit@dgn.org

\section{Einhaltung ethischer Richtlinien}

Interessenkonflikt. Siehe Interessenkonflikterklärung auf www.dgn.org/ leitlinien.

Für diesen Beitrag wurden von den Autoren keine Studien an Menschen oder Tieren durchgeführt. Für die aufgeführten Studien gelten die jeweils dort angegebenen ethischen Richtlinien.

\section{In eigener Sache

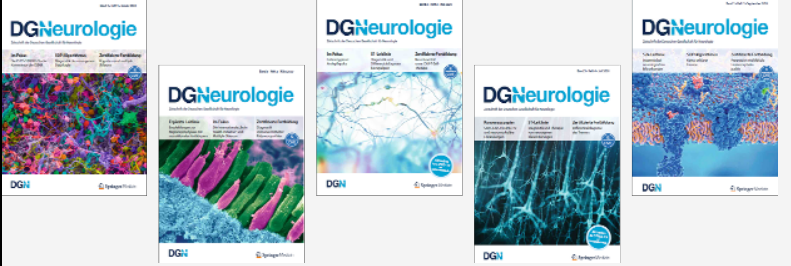 \\ Online-Inhalte der DGNeurologie kostenlos auf SpringerMedizin.de}

Der Zugang zur gesamten Online-Bibliothek ist in Ihrem Abonnement der Zeitschrift inbegriffen. Für den Zugang müssen Sie sich lediglich einmal über www.springermedizin.de/register registrieren.

Über diesen QR-Code schnell und einfach

registrieren:

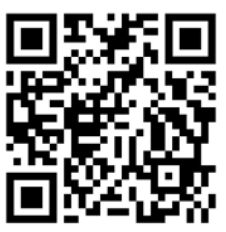

Bitte nutzen Sie für die Registrierung Vor- und Nachname und Lieferadresse wie beim Abonnement der Zeitschrift (siehe Adressaufkleber auf Ihrem Heft). So kann im System die Zugehörigkeit zu Ihrer Zeitschrift sichergestellt werden.

Aufgrund des Heilmittelwerbegesetzes dürfen die Inhalte der Website nur medizinischen Fachkreisen zur Verfügung gestellt werden. Bei der Anmeldung bitten wir Sie deshalb einen Berufsnachweis vorzulegen.

Bei Medizinern mit Mitgliedschaft in der deutschen Ärztekammer reicht die einheitliche Fortbildungsnummer (EFN). Alternativ schicken Sie eine Bestätigung des Arbeitgebers, Studiennachweis oder andere Zeugnisse an

kundenservice@springermedizin.de.

Mit Benutzername und Passwort haben Sie außerdem Zugang zu den freien Inhalten auf den Seiten von:

https://www.springermedizin.de/

https://www.aerztezeitung.de/

Sollten Fragen oder Probleme auftauchen, wenden Sie sich einfach an Ihren Kundenservice:

kundenservice@springermedizin.de 